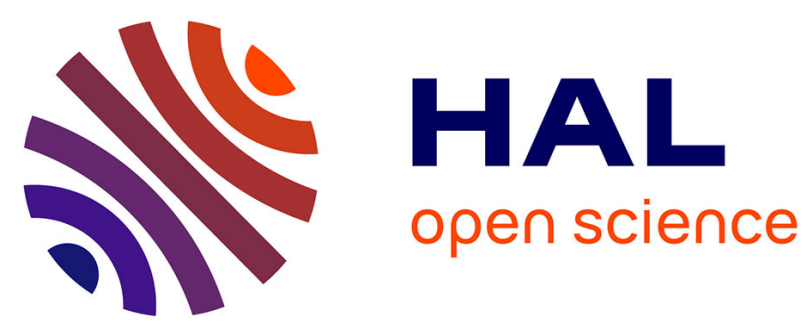

\title{
Physical Properties of Interfacial Layers Developed on Weathered Silicates: A Case Study Based on Labradorite Feldspar
}

Bastien Wild, Damien Daval, Jean-Sébastien Micha, Ian Bourg, Claire E White, Alejandro Fernandez-Martinez

\section{To cite this version:}

Bastien Wild, Damien Daval, Jean-Sébastien Micha, Ian Bourg, Claire E White, et al.. Physical Properties of Interfacial Layers Developed on Weathered Silicates: A Case Study Based on Labradorite Feldspar. Journal of Physical Chemistry C, 2019, 123 (40), pp.24520-24532. 10.1021/acs.jpcc.9b05491 . hal-02372378

\section{HAL Id: hal-02372378 https://hal.science/hal-02372378}

Submitted on 20 Nov 2019

HAL is a multi-disciplinary open access archive for the deposit and dissemination of scientific research documents, whether they are published or not. The documents may come from teaching and research institutions in France or abroad, or from public or private research centers.
L'archive ouverte pluridisciplinaire HAL, est destinée au dépôt et à la diffusion de documents scientifiques de niveau recherche, publiés ou non, émanant des établissements d'enseignement et de recherche français ou étrangers, des laboratoires publics ou privés. 
$1 \quad$ Physical Properties of Interfacial Layers Developed

4 Bastien Wild ${ }^{1,2,3,}$, Damien Daval ${ }^{1}$, Jean-Sébastien Micha ${ }^{4}$, Ian C. Bourg ${ }^{3,5}$, Claire E. White,

5 and Alejandro Fernandez-Martinez ${ }^{6}$

6

7 AUTHOR ADDRESS

$8 \quad{ }^{1}$ Laboratoire d'Hydrologie et de Géochimie de Strasbourg (LHyGeS), Université de Strasbourg

9 /EOST-CNRS UMR 7517, 1 Rue Blessig, 67000 Strasbourg, France

$10{ }^{2}$ Andlinger Center for Energy and the Environment, Princeton University, Princeton, NJ 08544,

11 USA

$12{ }^{3}$ Department of Civil and Environmental Engineering, Princeton University, Princeton, NJ

13 08544, USA

$14{ }^{4}$ CEA - Grenoble/INAC/SPrAM, 17 rue des Martyrs, 38041, Grenoble, France

$15{ }^{5}$ Princeton Environmental Institute, Princeton University, Princeton, NJ 08544, USA

$16{ }^{6}$ Univ. Grenoble Alpes, Univ. Savoie Mont Blanc, CNRS, IRD, IFSTTAR, ISTerre, Grenoble

1738000 , France

18 *Corresponding Author : bwild@princeton.edu ; (609) 9866332 
20 ABSTRACT

21 Amorphous silica-rich surface layers (ASSLs) formed at the interface between silicate materials

22 and reacting fluids are known to strongly influence, at least in some cases, the dissolution rates

23 of silicate phases including soil minerals, glasses, and cements. However, the factors governing

24 the formation of these ASSLs remain largely unknown. Here, we outline a novel approach that

25 uses recent developments in vertical scanning interferometry (VSI) and in-situ synchrotron-based

26 X-ray reflectivity (XRR) to directly follow the development of ASSLs, and the evolution of their

27 physical properties, on a model silicate (labradorite feldspar). Our approach enabled

28 independently probing the reactivities of the outer (bulk fluid/ASSL) interface and of the inner

29 (ASSL/pristine mineral) interface in-situ, providing a detailed picture of the temporal evolution

30 of the fluid-mineral interface. We investigated the effects of $\mathrm{pH}, \mathrm{SiO}_{2}(\mathrm{aq})$ concentration,

31 crystallographic orientation, and temperature on the layer thickness, density, and reactivity as

32 well as on the dissolution rate of the primary mineral. The dissolution rate of labradorite crystals

33 increased with temperature, according to an apparent activation energy of $\sim 57 \mathrm{~kJ} \mathrm{~mol}^{-1}$ and

34 showed no significant difference between crystallographic faces. Both labradorite and ASSL

35 dissolution rates decreased as circum-neutral $\mathrm{pH}$ conditions were approached. $\mathrm{High} \mathrm{SiO}_{2}(\mathrm{aq})$

36 concentrations resulted in (i) decreased apparent dissolution rates, while far-from-equilibrium

37 conditions with respect to labradorite were maintained in the bulk fluid, and (ii) an increasing

38 ASSL density when combined with low temperature and close-to-neutral pH. Our results

39 highlight the importance of ASSLs and their complex impact on the dissolution process. In

40 particular, our results provide evidence of a discrepancy between bulk fluid conditions, generally

41 probed and reported, and those actually operating at the interface with the dissolving primary 
42 phase, which are of more direct relevance to the dissolution process but are still largely

43 unknown.

\section{INTRODUCTION}

Amorphous silica-rich surface layers (ASSLs) are hydrated, nanoporous, metastable

48 phases that form at the interface between reactive fluids and a variety of silicate materials

49 including olivine ${ }^{1-4}$, wollastonite ${ }^{5-9}$, feldspars ${ }^{10-14}$, and glasses ${ }^{15-18}$. These layers, also called

50 surface alteration layer (SAL), form ubiquitously from laboratory to field settings ${ }^{19-21}$. They play

51 a key role in controlling the dissolution rates of silicate materials with important implications for

52 several critical environmental and societal challenges including the degradation of cement

53 infrastructure ${ }^{22}$, the long-term storage security of nuclear waste ${ }^{18,23}$, and the feasibility of

54 enhancing silicate weathering as a large-scale $\mathrm{CO}_{2}$ capture technology ${ }^{24,25}$.

55 While the existence of ASSLs has been known or hypothesized for at least 80 years ${ }^{26}$,

56 the mechanisms underlying their formation and their influence on the dissolution rate of the

57 primary material remain poorly understood. This lack of mechanistic understanding is illustrated

58 by two fundamental disagreements. The first of these concerns whether ASSLs form by leaching

59 of soluble elements (e.g., $\mathrm{Ca}, \mathrm{K}, \mathrm{Mg}, \mathrm{Na}$ ) from the primary mineral or, alternatively, by

60 dissolution of the primary mineral followed by precipitation of an amorphous Si-rich phase. The

61 first hypothesis (referred to as the "leached layer" hypothesis) has represented the prevailing

62 paradigm for decades ${ }^{27,28}$. It is consistent with ion and photon probe results suggesting that the

63 elemental profiles of reactive species and reaction products are anticorrelated within the ASSL

$64{ }^{29-38}$. The alternative "dissolution-reprecipitation" hypothesis ${ }^{39}$ is supported by transmission 
65 electron microscopy observations that indicate an absence of compositional gradients within the 66 ASSL $^{13}$ and atom-probe tomography measurements of altered glass samples that reveal an 67 atomically sharp inner interface \{Gin, 2017; Hellmann, 2015\}, which has led to the suggestion 68 that the compositional gradients observed in the ion and photon probe results may be artifacts 69 associated with low lateral resolution ${ }^{20}$. It is also supported by indirect evidence, in some cases, 70 of fluid-mineral interactions occurring through the layer and of mineral dissolution at the 71 interface between the ASSL and the pristine mineral surface ${ }^{40}$, due to the presence of a thin fluid 72 film at the inner interface $\{$ Hellmann, 2012\}.

73 The second fundamental disagreement concerns the extent to which the ASSL behaves as 74 a barrier to transport. The historical approach assumes that the dissolution rate of the pristine 75 silicate mineral surface follows transition state theory (TST) and depends only on the chemistry 76 of the bulk aqueous solution ${ }^{41}$. This "primary dissolution control" approach was based on 77 studies where the presence of ASSLs had little or no effect on the dissolution rate or where 78 evidence of diffusive processes was dismissed as experimental artefacts ${ }^{10,42-44}$. While challenged 79 more than 20 years ago by both contradictory experimental results 45,46 and theoretical 80 inconsistencies $^{47,48}$, this hypothesis is still widely used in reactive transport codes. An important 81 alternative (referred to as the "ASSL dissolution control" approach) consists in applying TST 82 while treating the thermodynamic properties of the ASSL (rather than the primary mineral) as a 83 driver of the overall weathering process ${ }^{45,49-53}$. In essence, this approach treats the ASSL as an 84 activated complex in the sense of TST, the experimental verification of which is still a subject of 85 debate ${ }^{54}$. A second important alternative (referred to as "primary dissolution and transport 86 control") suggests that, in addition to the dissolution of the primary mineral, transport limitations

87 to the diffusion of reactive species across the ASSL must also be accounted for ${ }^{9,18,55-59}$. 
One reason for the existence of competing modeling frameworks outlined above is the

89 relatively limited availability of dissolution data relative to the vast range of conditions to be

90 explored in terms of silicate mineral chemistry, aqueous chemistry, and temperature. For

91 example, with the notable exception of results obtained on wollastonite over a wide $\mathrm{pH}$ range ${ }^{20}$,

92 most studies supporting the hypothesis that chemical affinity between the bulk fluid and the

93 primary mineral plays an important role were performed under low $\mathrm{pH}$ conditions, which favor

94 the formation of non-passivating layers ${ }^{14}$, similar to the work by Lagache ${ }^{10}$ more than 40 years

95 ago. Similarly, parameters such as the redox potential of the solution that have not been

96 systematically examined may have a direct impact on ASSL texture and resulting diffusivity ${ }^{60-}$

$97 \quad 62$. In short, competing interpretations regarding the mechanism and impact of ASSL formation

98 on the overall silicate dissolution rate for identical materials (e.g., Schott, et al. ${ }^{8}$ vs. Ruiz-

99 Agudo, et al. ${ }^{7}$ or Hellmann, et al. ${ }^{63}$ vs. Gin, et al. ${ }^{18}$ ) may simply reflect differences in reacting

100 conditions combined with insufficient knowledge of the thermodynamic and transport properties

101 of ASSLs.

102 The upshot of this is that an improved understanding of the fundamental properties of

103 ASSLs is likely key to resolving the disagreements outlined above ${ }^{25,64}$. Existing data on the

104 properties of ASSLs remains relatively limited for several reasons. First, standard dissolution

105 experiments yield relatively low accuracy estimates of the growth rate of the ASSL as quantified

106 indirectly from small deviations between the stoichiometric composition of released elements

107 and that of the pristine solid. Second, reconstructions of mineral dissolution rates and ASSL

108 thickness from elemental release data are challenged by uncertainties related to the specific

109 surface area of the reactive interface, typically estimated as the Brunauer-Emmett-Teller (BET)

110 surface area of the fresh mineral powder ${ }^{65}$. Such normalization may not account for the temporal 
111 evolution of reactive surface area or spatial variability of the dissolution rate, while the surface

112 area measurement itself may be inconsistent and carry large and often poorly constrained

113 uncertainties ${ }^{66}$. Finally, the few existing detailed characterizations of ASSLs have been carried

114 using destructive techniques and, therefore, they inherently do not reveal the time-dependence of 115 ASSL properties.

116 To date, the transport properties of nanoporous surface layers developed on silicate 117 materials have represented a recurrent topic for material scientists in general and have been 118 addressed by theoretical and experimental studies beyond the field of Geosciences ${ }^{57,67-71}$. 119 Importantly, such transport properties are critically inherited from the (yet to be determined) 120 physicochemical evolution of the silica-rich surface layers, which represent some of the central 121 insights to this study.

122 The aim of the present study is to utilize a novel combination of approaches to follow the 123 evolution of the physical properties of ASSLs in-situ, providing direct information into ASSL 124 thickness and density and indirect insights into the local physico-chemical conditions prevailing 125 at the inner (pristine mineral/ASSL) interface. We use X-ray reflectivity (XRR) data to track the 126 temporal evolution of ASSL thickness and density. Complementary vertical scanning 127 interferometry (VSI) measurements are performed to track the evolution of the outer (ASSL/bulk 128 solution) interface. Our methodology circumvents the aforementioned challenges and enables 129 probing mineral reactivity and layer formation at low solid/fluid ratios $\left(\sim 21 \mathrm{~mm}^{2}\right.$ for $800 \mathrm{ml}$ of 130 solution), ensuring that far-from-equilibrium conditions with respect to the dissolving crystal can 131 be maintained. Layer thickness and surface retreat data are combined to determine the rate of 132 retreat of the inner interface, enabling the calculation of the dissolution rate of the primary 133 labradorite feldspar located underneath the ASSLs. Overall, this study provides a novel 
134 characterization of the physicochemical properties of nanoporous surface layers developed on a

135 reference silicate material (feldspar), with possible consequences for the dissolution kinetics of 136 the underlying substrate.

METHODS

\section{Sample preparation}

141 provided by the Mineralogical \& Geological Museum of Harvard University (Ref. 142 MGMH\#135998). They consist of transparent gem-grade crystals with a composition of $143 A b_{39} A n_{60} O r_{1}{ }^{72}$. Samples of about $7 \mathrm{~mm} \times 3 \mathrm{~mm}$ suited for XRR, VSI, and atomic force

144 microscopy (AFM) measurements were prepared following standard procedures previously 145 described ${ }^{14}$. Briefly, euhedral crystals were cut with a diamond saw following (001) preferential 146 cleavage planes and polished down to the nanometer scale using colloidal silica polishing 147 suspension. One (010) surface was also prepared. Their orientation was verified by indexing 148 electron backscatter diffraction (EBSD) patterns obtained on a Tescan Vega 2 scanning electron 149 microscope (SEM).

$150 \quad$ Labradorite dissolution and ASSL formation

151 Labradorite samples were reacted in $\mathrm{pH}$ environments ranging from 1.5 to 4 and 152 experiments were run for durations of about 1 hour to more than 35 days as required to form 153 measurable (i.e., $>5 \mathrm{~nm}$ thick) ASSLs at the fluid-mineral interface. Samples were incubated at $15480^{\circ} \mathrm{C}$ using (PTFE) Savillex ${ }^{\circledR}$ reactors equipped with a custom PTFE stirring system ${ }^{14}$. Reactors 155 were filled with a reacting fluid consisting of Milli-Q water whose $\mathrm{pH}$ had been previously 156 adjusted with high-grade $\mathrm{HCl}(37 \%$, ACS reagent) and, for some experiments, saturated with 157 respect to amorphous silica using sodium metasilicate, nonahydrate (Sigma Aldrich ${ }^{\circledR},>98 \%$ ). 
158 The $\mathrm{pH}$ was regularly controlled and adjusted if necessary. A summary of experiments and 159 experimental conditions can be found in Tables S1-S6. The saturation indices for labradorite and 160 amorphous silica at $80{ }^{\circ} \mathrm{C}$ were calculated using the Chess ${ }^{\circledR}$ software and the Chess ${ }^{\circledR}$ tdb 161 database. After reaction, samples were briefly rinsed in Milli-Q water and kept at room 162 temperature in aqueous solutions close to saturation with respect to amorphous silica until XRR 163 measurement to avoid subsequent dehydration or dissolution. For experiments carried out over 164 short durations (up to 94 hours), crystals were directly reacted in-situ over the course of the XRR 165 measurements with an experimental setup enabling fluid circulation at controlled temperature in 166 a custom flow-through cell with Kapton windows (Figure 1).
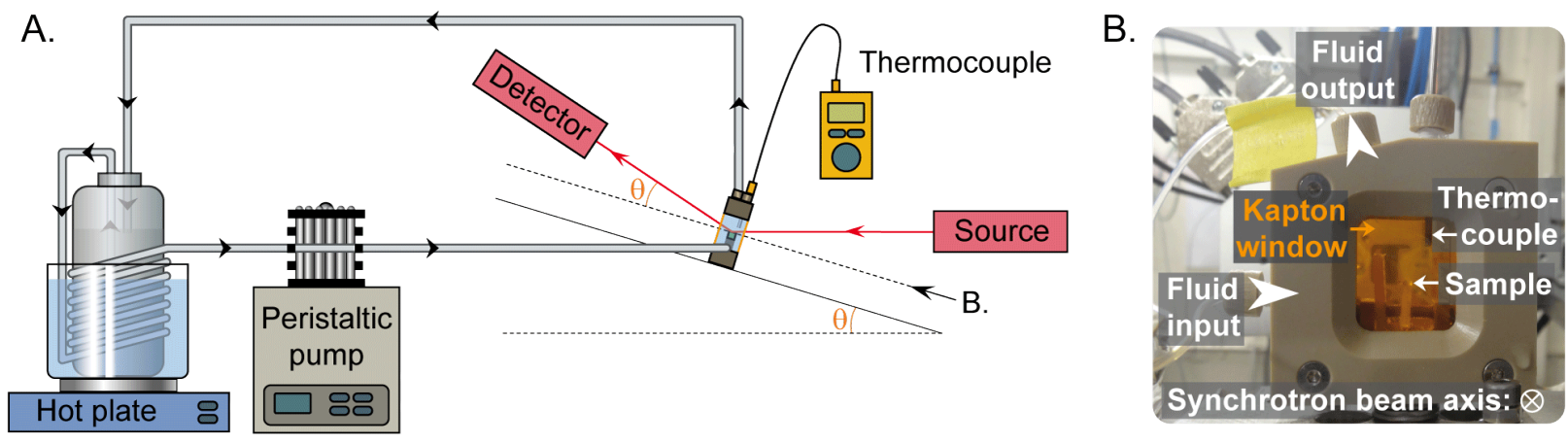

168 Figure 1. overview of the experimental setup (A) and front view of the flow-through cell 169 designed for in-situ experiments (B). Fluid temperature within the cell was verified with a 170 thermocouple.

174 prior to reaction. A portion of the surface of samples summarized in Tables S5 and S6 was then 175 masked with a room-temperature-vulcanizing (RTV) silicone glue spot in order to create a non176 reacted reference by avoiding fluid-mineral contact at this specific location. After reaction, the 
177 global retreat of the surface due to crystal dissolution was quantified using topography images

178 recorded by VSI on reacted samples after removal of the mask. The absolute dissolution rate at

179 the fluid/layer interface is estimated as $r=(\Delta h / \Delta t) \times\left(1 / V_{\mathrm{m}}\right)$, where $r$ stands for the absolute

180 dissolution rate $\left(\mathrm{mol} \mathrm{m}^{-2} \mathrm{~s}^{-1}\right), \Delta h$ is the surface retreat $(\mathrm{m}), \Delta t$ is the alteration duration (s), and

$181 V_{m}$ is the molar volume of labradorite $\left(\mathrm{m}^{3} \mathrm{~mol}^{-1}\right)^{73}$. Topography images and profiles were

182 analyzed using SPIP software.

183 The roughness of the outer interface, $\sigma_{e x}$, was determined based on AFM (Bruker

184 Multimode AFM) and VSI measurements conducted on three representative portions of the

185 surface with dimensions of $1 \mu \mathrm{m} \times 1 \mu \mathrm{m}(\mathrm{AFM})$ and $125 \mu \mathrm{m} \times 125 \mu \mathrm{m}(\mathrm{VSI})$. The roughness

186 value was calculated using Gwyddion software ${ }^{74}$ as the root mean square of the deviations in

187 height $z$ from the mean image data plane $z_{0}$. Nanoscope Analysis software and Gwyddion were

188 used to visualize and process AFM data including particle size measurements.

\section{Internal properties of the ASSL by in-situ X-ray reflectivity experiments}

X-ray reflectivity measurements were performed at the European Synchrotron Radiation

191 Facility (ESRF) at the French BM32 beamline (CRG-IF). $27 \mathrm{keV}$ X-rays (wavelength, $\lambda=$ $1920.0459 \mathrm{~nm})$ were used to ensure sufficient transmission $(\mathrm{T} \sim 68.5 \%)$ through the $\sim 1 \mathrm{~cm}$ thick

193 solution in the cell. Reflectivity patterns were acquired for $2 \theta$ angles ranging between $0^{\circ}$ and $1^{\circ}$

194 (corresponding to scattering vectors ranging between 0.0 and $0.5 \AA^{-1}$ ). For the pre-reacted 195 samples (i.e., samples reacted prior to the XRR measurement campaign), the dissolution 196 experiments had different onset times and were all stopped one day prior to the XRR campaign, 197 yielding samples altered for a range of desired time periods. The pre-reacted samples were then 198 transported to the ESRF in a near-neutral $\mathrm{pH}$ solution ( $\mathrm{pH}$ 6.5) saturated with respect to 199 amorphous silica. Once at the ESRF, pre-reacted samples were analyzed in our custom cell 
200 (Figure 1B) filled with Milli-Q water at room temperature. For the in-situ experiments, unreacted 201 samples were placed in the same cells circulated with fluid of desired chemistry at $80^{\circ} \mathrm{C}$ and 202 patterns were acquired every 5 to 15 min depending on the growth rate of the ASSL (Figure 1).

204 IGOR Pro environment. Interfacial roughness, layer density (initially set to that of pure 205 amorphous silica), and layer thickness were refined to match the scattering length density (SLD) 206 profile $\mathrm{q}(z)$ in the direction perpendicular to the mineral-water interface. The strategy used to fit 207 the experimental XRR patterns involved the minimum number of layers required to obtain a 208 satisfactory fit following Nelson ${ }^{75}$. Discrepancies between the model and data were quantified

209 by the $\chi^{2}$ parameter as defined by Nelson ${ }^{75}$, which was minimized by adjusting the thickness 210 and SLD parameters of each layer as well as inner and outer roughness values following a two211 step procedure including genetic optimization ${ }^{76}$ and the Levenberg-Marquardt method ${ }^{77}$. As 212 shown in Figure S1, some factors (for example, the existence of local minima) were found to 213 have non-monotonic influence on fit quality as quantified by the $\chi^{2}$ value. Hence, the reliability 214 of data modeling was ensured by including genetic optimization as the first step of the fitting 215 procedure. All possible solutions were analyzed manually and discarded if necessary (for 216 instance in the case non-realistically high density values).

\section{RESULTS}

\section{Formation of ASSLs and in-situ evolution of their physical properties}

The formation of ASSLs at the fluid-mineral interface was observed by XRR for all 221 tested conditions, i.e. $\mathrm{pH}=1.5$ to $\mathrm{pH}=4,80^{\circ} \mathrm{C}$ or $25^{\circ} \mathrm{C}$, in aqueous solutions that were either 222 saturated or not with respect to amorphous silica. As a general trend, ASSLs' growth rate 
223 decreases for experiments conducted at higher $\mathrm{pH}$ values, in solutions saturated with respect to 224 amorphous silica or at lower temperature, all other conditions being kept constant. The ASSL 225 was found to grow at a nearly constant rate in most conditions as revealed by the linear trends in 226 Figure 2, with the notable exception of the longest experiments conducted at $\mathrm{pH}=3$ and 4 227 (duration $\geq 1$ day). Comparison between results at different $\mathrm{pH}$ values revealed a near-linear $\mathrm{pH}$ 228 dependence of the logarithm of the growth rate (Figure 3). Use of a lower temperature (25 vs. $22980^{\circ} \mathrm{C}$ at $\mathrm{pH}=1.5$ ) in saturated solution led to a drop of the dissolution rate by a factor of $\sim 50$ 230 (orange symbol, Figure 3). Fluid saturation with respect to amorphous silica led to a decrease of 231 the growth rate by a factor ranging from $\sim 4$ at $\mathrm{pH}=1.5$ to nearly 30 at $\mathrm{pH}=4$ (diamonds versus 232 squares, Figure 3). 


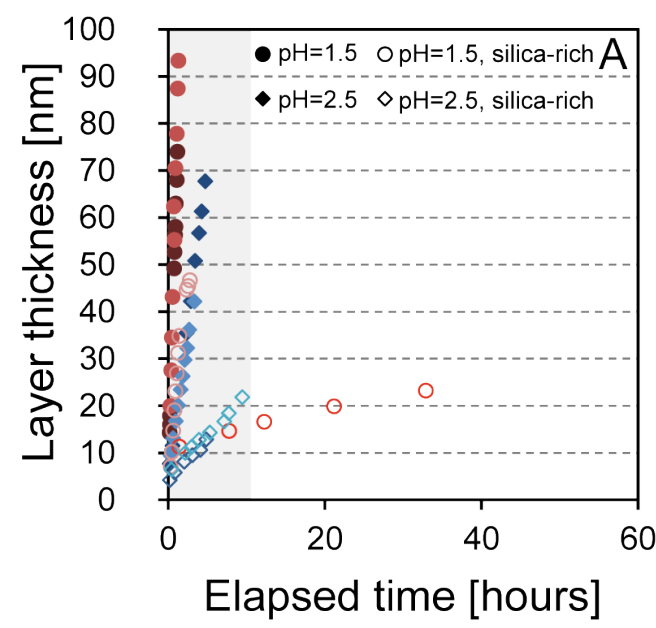

- XRR1-1.5-80-0-001

- XRR2-1.5-80-0-001

- XRR3-2.5-80-0-001

- XRR4-2.5-80-0-010

OXRR9-1.5-25-SiO2-001

O XRR10-1.5-80-SiO2-001

$\diamond$ XRR11-2.5-80-SiO2-001

$\diamond$ XRR12-2.5-80-SiO2-001
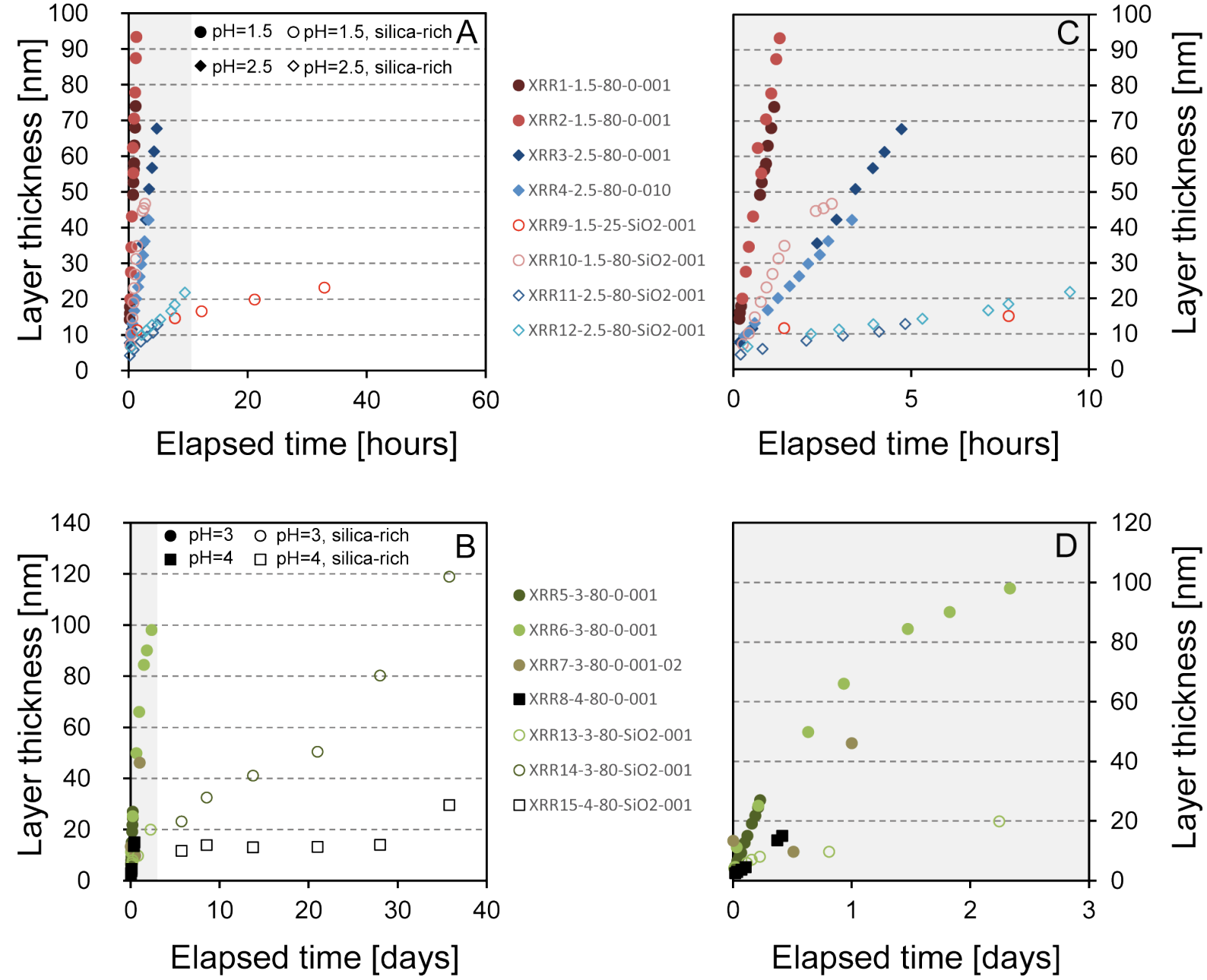

Elapsed time [days]

234 Figure 2. Temporal evolution of layer thickness as measured by X-ray reflectivity. Layers'

235 growth was generally faster for experiments at $\mathrm{pH} \leq 2.5$ (A) compared to experiments at $\mathrm{pH}>$

2362.5 (B), and slower for experiments conducted with fluids saturated with respect to amorphous

237 silica (open data points) compared to their non-saturated counterparts (filled data points). All

238 experiments were conducted at $80^{\circ} \mathrm{C}$ with the exception of experiment XRR10-1.5-25-SiO2-001

239 (red open circles in panel A), conducted at $25^{\circ} \mathrm{C}$. 


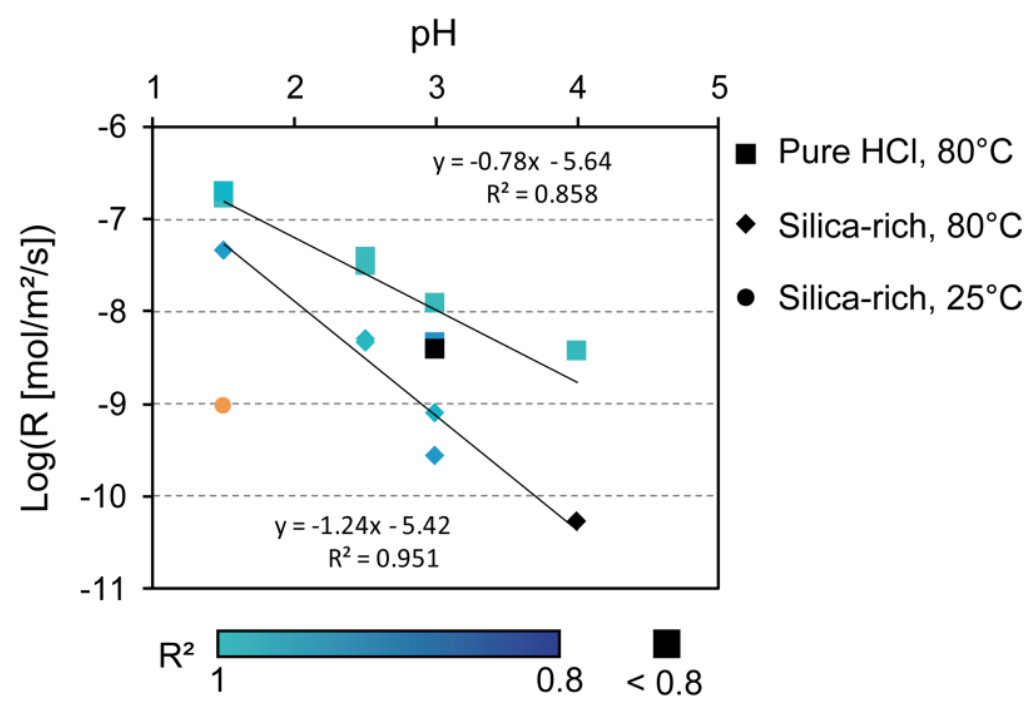

242 Figure 3. $\mathrm{pH}$-dependence at $80^{\circ} \mathrm{C}$ of layer growth rate represented as moles of labradorite per 243 square meter converted each second into layer (labradorite $\rightarrow$ layer). Diamonds and squares 244 represent experiments where the fluid was saturated or not with respect to amorphous silica, 245 respectively. For each experiment represented here, the color quantifies the regression coefficient 246 associated to linear regression of the temporal evolution of the layer thickness (cf. Figure 2) 247 according to the color scale below the graph. The orange data point corresponds to the 248 experiment conducted at $25^{\circ} \mathrm{C}$ in a silica-rich fluid.

Measured SLD values ranged from 10.6 to $21.510^{-6} \AA^{-1}$, which would correspond to 252 densities of $\sim 1.25$ and $2.53 \mathrm{~g} \mathrm{~cm}^{-3}$ under the hypothesis that ASSL are composed of pure silica $253\left(\mathrm{SiO}_{2}\right)$ (Figure 4). No significant SLD difference (within the uncertainty of $\pm 5 \%$ ) was detected 254 between ASSLs grown on different crystallographic surfaces [(001) vs. (010)]. Experiments 255 conducted in fluids combining high $\mathrm{Si}$ concentrations $(\sim 145 \mathrm{ppm})$ and weakly acidic $\mathrm{pH}$ or low 256 temperature (e.g. experiments XRR10-1.5-25-SiO2, XRR14-3-80-SiO2-001 or XRR15-4-80$257 \mathrm{SiO} 2-001)$ tended to exhibit constant or increasing SLD trends over time, suggesting progressive 
258 densification. Conversely, experiments conducted in fluids with low Si concentrations $(<200$

259 ppb) exhibited decreasing, constant, or non-monotonous SLD trends. The experiment conducted

260 at $25^{\circ} \mathrm{C}$ in a silica-rich fluid at $\mathrm{pH}=1.5$ exhibited a significantly lower mean SLD compared to its

261 counterpart conducted at $80^{\circ} \mathrm{C}(12.8 \pm 0.9$ vs. $14.8 \pm 0.5$ respectively $)$. Measurements performed

262 after completion of experiments XRR9-1.5-80-SiO2-001, XRR11-2.5-80-SiO2-001 and XRR13-

263 3-80-SiO2-001 revealed that layers dried and measured immediately after in-situ dissolution tend

264 to exhibit lower SLD values than previous measurements corresponding to their hydrated

265 counterparts (Table S3).
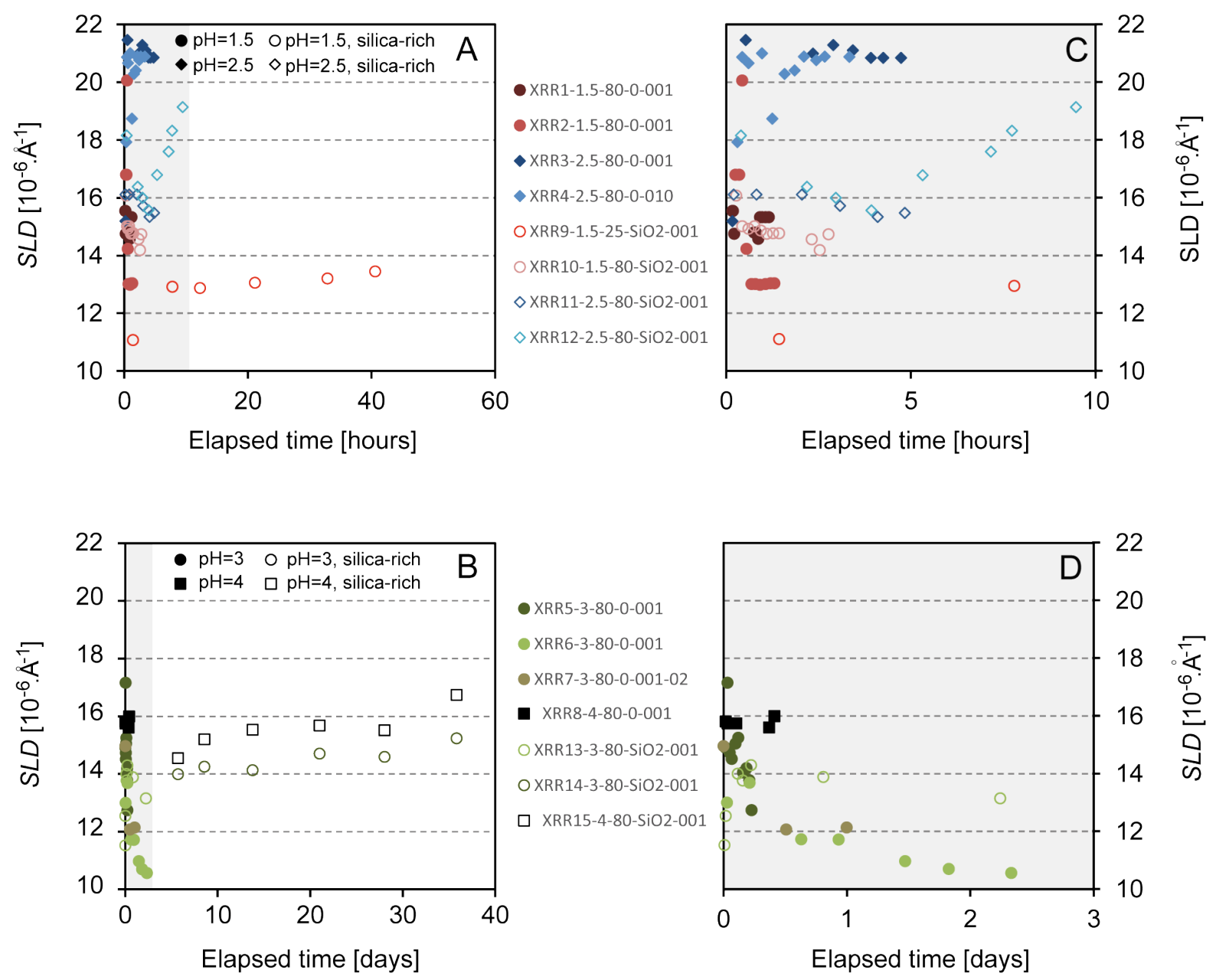

267 Figure 4. Temporal evolution of the scattering length density of ASSLs as measured by X-ray

268 reflectivity for experiments at $\mathrm{pH} \leq 2.5(\mathrm{~A}, \mathrm{C})$ and $\mathrm{pH}>2.5(\mathrm{~B}, \mathrm{D})$. Open data points correspond 
269 to experiments conducted with fluids saturated with respect to amorphous silica. C and D 270 correspond to close-up views of the regions indicated by the shaded areas on plots A and B, 271 respectively. All experiments were conducted at $80^{\circ} \mathrm{C}$ with the exception of experiment XRR10$272 \quad 1.5-25-\mathrm{SiO} 2-001$ (red open circles in panel A), conducted at $25^{\circ} \mathrm{C}$.

273

274

275

\section{Reactivity and evolution of the outer interface}

The global retreat of the outer surface compared to a masked reference (Figure 5), as

277 measured using VSI, was used to probe the reactivity at the outer (ASSL/bulk solution) interface

278 in all tested conditions (see Tables S5 and S6) on a set of samples distinct from those dedicated 279 to XRR measurements.
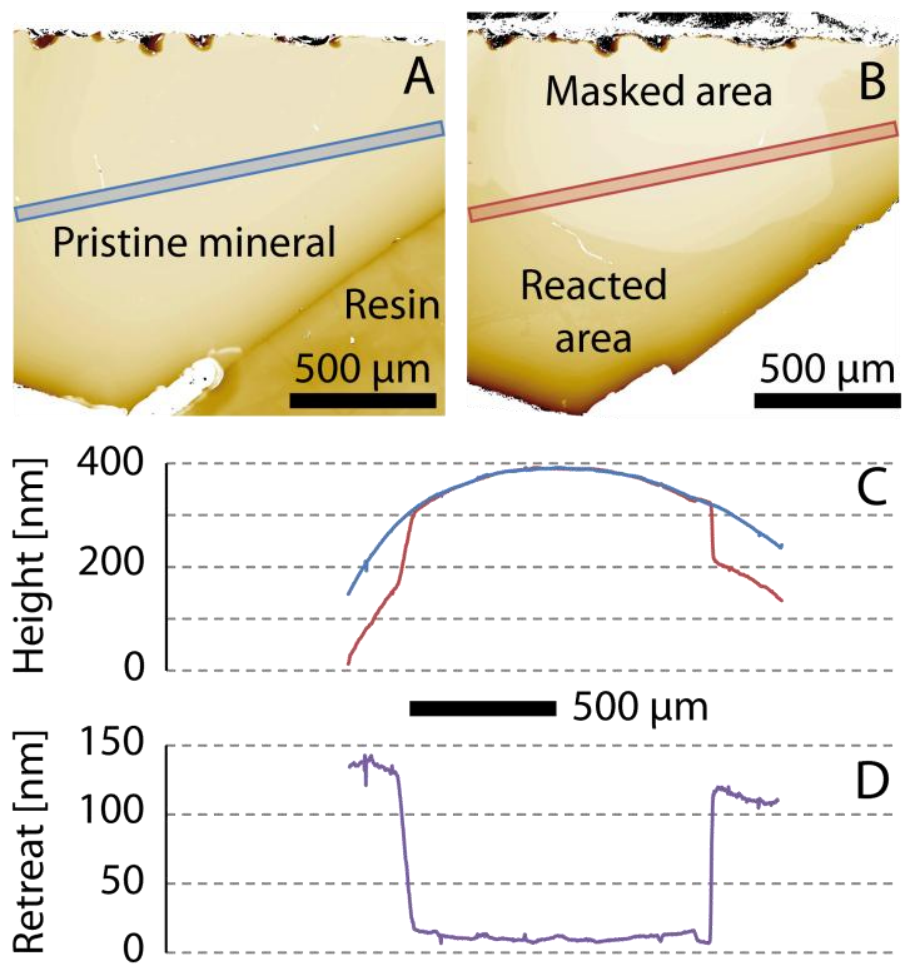

281 Figure 5. Typical measurement of surface retreat based on topography maps acquired by VSI 282 before (a) and after (b) the dissolution process (here a labradorite sample weathered for 35 days 
283 at $80^{\circ} \mathrm{C}$ in a fluid at $\mathrm{pH}=3$ saturated with respect to amorphous silica). This specific sample was 284 detached from the resin after reaction to facilitate VSI alignment. Height profiles recorded before 285 (blue) and after (red) weathering through the non-reacted masked area are superimposed (c) and 286 subtracted to highlight the overall surface retreat. Some variation on the retreat can be seen, 287 which is consistent with literature on intrinsic variability of the dissolution rate and profile 288 subtraction at the mm scale.

290 Assuming isovolumetric weathering, dissolution rates of the outer interface were reconstructed 291 from VSI data and showed a significant decrease with increasing pH (Figure 6). Dissolution rates

292 were smaller when the bulk fluid was saturated with respect to amorphous silica, indicating a 293 decreased reactivity of the ASSL at the outer interface by a factor of 4 to 80 . The high vertical 294 resolution of the VSI measurements (down to a few $\mathrm{nm}$ ) enabled estimating the apparent 295 activation energy $\left(E_{a}\right)$ of the ASSL dissolution process based on kinetic data collected at $T_{1}=$ $29680^{\circ} \mathrm{C}$ and $T_{2}=25^{\circ} \mathrm{C}$ for experiments with a fluid at $\mathrm{pH}=1.5$ saturated with respect to amorphous 297 silica, as:

$$
E_{a}=R \frac{T_{1} T_{2}}{T_{1}-T_{2}} \ln \left(\frac{r_{1}}{r_{2}}\right)
$$

299 where $r$ is the dissolution rate of ASSL. In these conditions, the 23 -fold decrease in ASSL 300 dissolution rate between $80^{\circ} \mathrm{C}$ and $25^{\circ} \mathrm{C}$ corresponds to an $E_{\mathrm{a}}$ value of $50 \mathrm{~kJ} \mathrm{~mol}^{-1}$. 


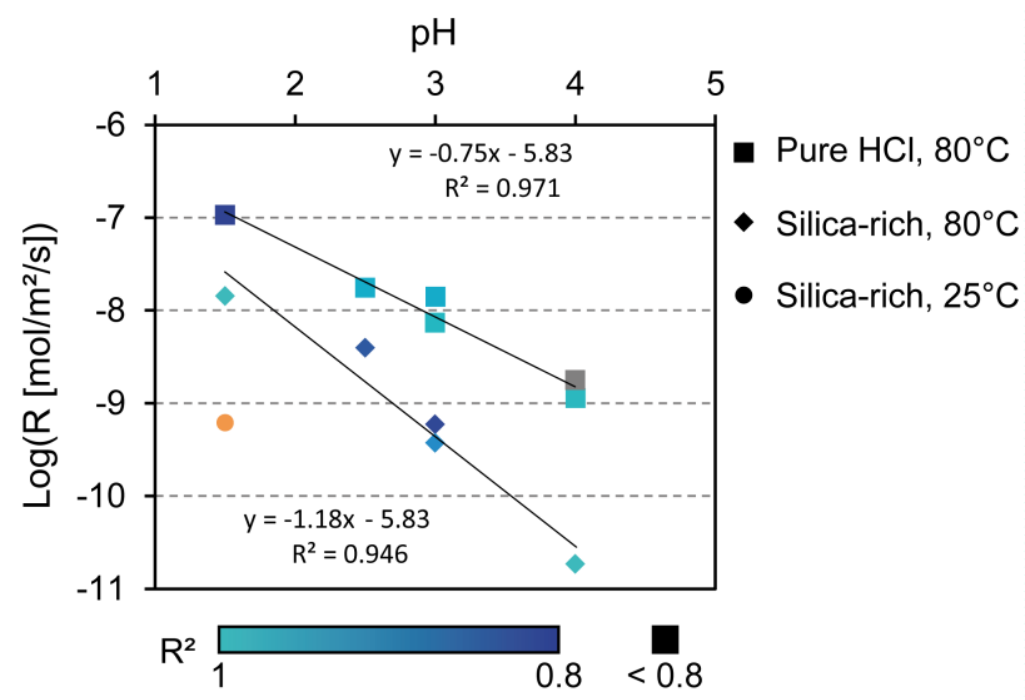

303 Figure 6. $\mathrm{pH}$-dependence of layer dissolution rate (layer $\rightarrow$ dissolved species) at $80^{\circ} \mathrm{C}$.

304 Diamonds and squares represent experiments where the fluid was saturated or not with respect to 305 amorphous silica, respectively. For each experiment represented here, the color quantifies the

306 regression coefficient associated to linear regression of the temporal retreat of the outer

307 fluid/layer interface (cf. Figure 7) according to the color scale below the graph. Grey square:

308 based on 2 retreat values. The orange data point corresponds to the experiment conducted at $30925^{\circ} \mathrm{C}$ in a silica-rich fluid.
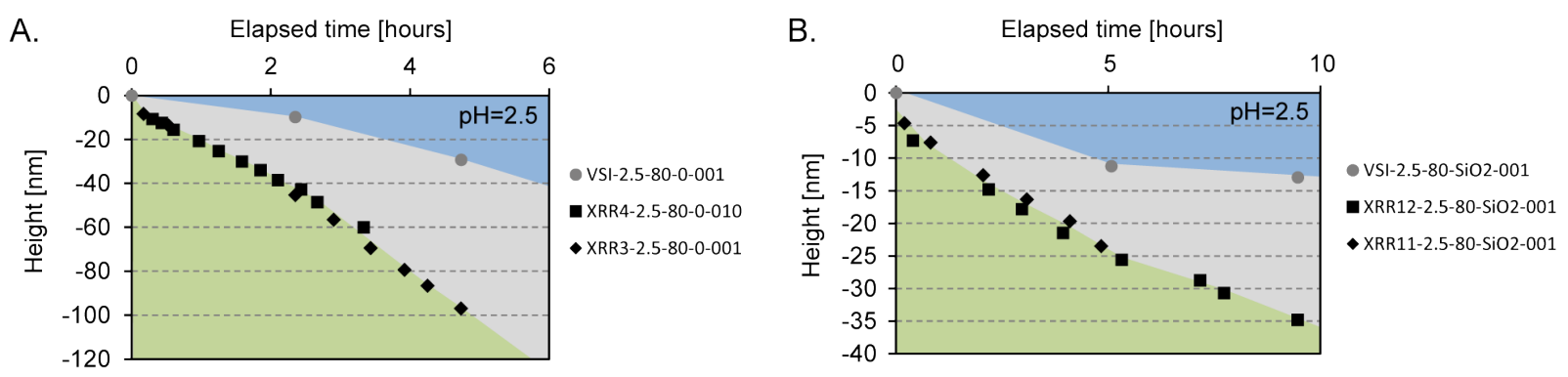

312 Figure 7. Temporal evolution of ASSL thickness (grey) at the interface between mineral (green)

313 and fluid (blue) for experiments conducted at $80^{\circ} \mathrm{C}, \mathrm{pH}=2.5$ ), using a fluid that was saturated $314\left(\mathrm{SiO}_{2}\right.$, panel B) or not (0, panel A) with respect to amorphous silica. Grey dots correspond to VSI 
measurements of the surface retreat compared to a non-reacted reference (zero height) and track

316 the reactivity of the outer interface. Black diamonds and squares correspond to X-ray reflectivity

317 data corrected for surface retreat and track the temporal evolution of the inner interface. Colored

318 background is used to guide the eye. All experiments were conducted on (001) labradorite faces

319 with the exception of one experiment conducted on (010) (A). A summary of all experimental

320 conditions tested in this study can be found in Figure S3.

The roughness of the outer interface of a sample reacted at $\mathrm{pH}=3$ was measured before 324 and after dissolution on AFM and VSI data ${ }^{14,78}$. Both techniques yield roughness values of 325 similar order of magnitude, the VSI measurements being nevertheless systematically higher than 326 those from AFM. During the experiments, roughness increased from $\sigma_{e x}^{V S I}=17 \mathrm{~nm}$ and $\sigma_{e x}^{A F M}=7$

$327 \mathrm{~nm}$ to $\sigma_{e x}^{V S I}=65 \mathrm{~nm}$ and $\sigma_{e x}^{A F M}=36 \mathrm{~nm}$ as measured using VSI and AFM, respectively. AFM 328 measurements further showed the formation of a nanoscale botryoidal texture of the outer 329 interface exhibiting spherical particles with an average radius of $9.8 \pm 1.2 \mathrm{~nm}$ (Figure S2). In

330 order to estimate a maximal porosity formed by the silica beads constituting the layer (as 331 opposed to a dense packing of these particles), their arrangement at the outer interface was 332 studied based on AFM data. The intersection of particles with a plane located $9.8 \mathrm{~nm}$ below the 333 highest point of a representative portion of the fluid/layer interface yields a pore/particle ratio of 3343.2 , which yields a rough estimate of $\sim 0.76$ as an upper bound on the porosity of the ASSL. 
VSI and XRR data were combined to provide one of the first accurate representations of 338 the temporal evolution of the fluid-silicate interface during dissolution and layer formation 339 (Figure 7, Figure S3). In particular, the surface retreat $z_{\text {out }}$ measured by VSI was combined with 340 the ASSL thickness $\Delta z$ determined from XRR data to evaluate the absolute height of the inner 341 interface $z_{\text {in }}$ (black squares and diamonds, Figure 7) at each timestep $t$ :

$$
z_{\text {in }}(t)=-\Delta z(t)-\frac{z_{\text {out }}\left(t_{+1}\right)-z_{\text {out }}\left(t_{-1}\right)}{t_{+1}-t_{-1}} * t
$$

343 In equation $2, \Delta z(t)$ is evaluated at time $t$ by XRR, while $z_{\text {out }}\left(t_{+1}\right)$ and $z_{\text {out }}\left(t_{-1}\right)$ correspond to 344 absolute values of the surface retreat at the closest VSI measurement before and after XRR 345 measurement respectively. In most cases, the temporal evolution of the inner interface was linear 346 or made up of linear portions of curves, which indicates constant dissolution rate at given 347 experimental conditions. Linear regression of $z_{\text {in }}$ vs. time was used as a proxy to estimate the 348 overall reactivity of labradorite (i.e., the dissolution rate of the primary mineral). Of note, this 349 approach considers the ASSL/mineral boundary as a single interface since the two reaction fronts 350 located on each side of the thin fluid film often reported at the inner interface $\{$ Hellmann, 2012\}, 351 could not be resolved by XRR. The resulting retreat rates of the inner interface revealed a near 352 logarithmic dependence of the dissolution rate on $\mathrm{pH}$ (Figure 8). Saturation of the solution with 353 respect to amorphous silica decreased the dissolution rate by a factor ranging from $\sim 5$ at $\mathrm{pH}=$ 3541.5 to $\sim 50$ at $\mathrm{pH}=4$. A temperature decrease from $80^{\circ} \mathrm{C}$ to $25^{\circ} \mathrm{C}$ at $\mathrm{pH}=1.5$ yielded a 37 -fold 355 drop in dissolution rate corresponding to an apparent energy of activation of about $57 \mathrm{~kJ} \mathrm{~mol}^{-1}$. 


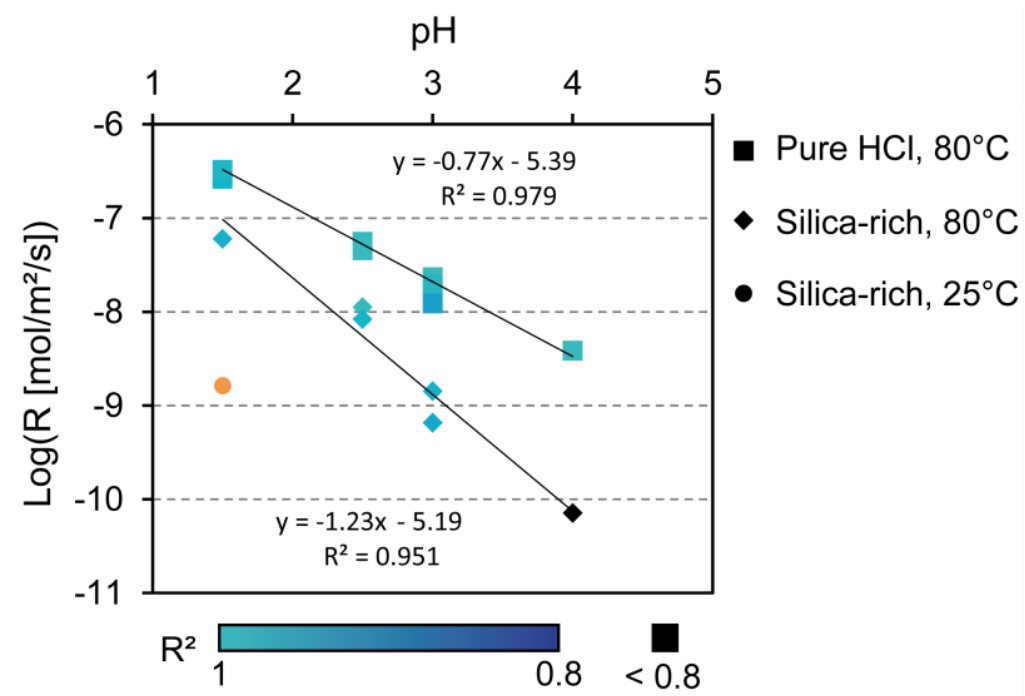

358 Figure 8. $\mathrm{pH}$-dependence at $80^{\circ} \mathrm{C}$ of labradorite dissolution rate

359 (labradorite $\rightarrow$ layer + dissolved species). Diamonds and squares represent experiments where

360 the fluid was respectively saturated or not with respect to amorphous silica. For each experiment

361 represented here, the color quantifies the regression coefficient associated to linear regressions of

362 the temporal retreat of the inner layer/mineral interface (cf. Figure 7) according to the color scale

363 below the graph. The orange data point corresponds to the experiment conducted at $25^{\circ} \mathrm{C}$ in a 364 silica-rich fluid.

\section{Fluid saturation state}

To verify that all our experiments were conducted at far-from-equilibrium conditions

369 with respect to labradorite dissolution (i.e., in the region where the dissolution rate is invariant

370 with saturation state, which defines the dissolution rate plateau), we used the final surface retreat

371 and layer thickness, along with the known sample geometric surface area $\left(\sim 2.8 \times 10^{-5} \mathrm{~m}^{2}\right)$ and

372 labradorite density $\left(\sim 9.8 \times 10^{-5} \mathrm{~m}^{3} \mathrm{~mol}^{-1}\right)$, to estimate the maximum possible fluid saturation state

373 with respect to labradorite at the end of our experiments. We note that rough samples edges 
374 resulting from diamond saw cutting were washed and covered with RTV glue prior to

375 experiment, which limited their contribution to cation release to the solution composition. As

376 shown in Table S1, Gibbs free energy $\left(\Delta G_{r}\right)$ values were all below the $\Delta G_{r}$ threshold value of -

$37741.8 \mathrm{~kJ} \mathrm{~mol}^{-1}$ where labradorite dissolution should be invariant with saturation as reported by 378 Taylor, et al. ${ }^{46}$.

\section{DISCUSSION} match the reflectivity data. These parameters include the layer thickness, density, as well as its

384 inner and outer roughness. Since the thickness of the layer primarily affects the periodicity of the 385 signal, which is not significantly impacted by density or roughness, this parameter can be 386 independently assessed with a high degree of confidence. The three other parameters are 387 somewhat correlated, so that the choice of a "best fit" solely based on the $\chi^{2}$ minimization 388 criterion is non-trivial (see e.g. Figure S1) and sometimes implicitly corresponds to favoring the 389 fitting of one portion of the curve relative to another. Indeed, since the $\chi^{2}$ value depends on the 390 proportion of data points accurately fitted by the model, it is possible to get a lower $\chi^{2}$ value with 391 a less relevant fit if parts of the curve containing little information (as opposed to "features of 392 interest" such as critical angle or well-defined oscillation region), account for a large proportion 393 of the considered data points.

394 In an attempt to alleviate the issue identified above, we constrained our estimate of the 395 roughness of the outer interface using roughness values measured on the same sample before and 396 after dissolution. We note that these independent roughness measurements had to be performed 
$397 e x$-situ, which prevented the acquisition of a time-series during the experiment. We associated as

398 a first approximation $\sigma_{e x}^{X R R}$ either to the linear interpolation of initial and final AFM-based

399 roughness $\left(\sigma_{e x}^{A F M}\right.$, cf. dark grey squares, Figure 9) or to the interpolation of the initial and final

400 averages between VSI- $\left(\sigma_{e x}^{V S I}\right)$ and AFM- $\left(\sigma_{e x}^{A F M}\right)$ based roughness (cf. light grey squares, Figure

401 9). Reflectivity measurements performed on dried layers (Table S3) were used to verify that any

402 observed discrepancy between $\sigma_{e x}^{X R R}$ and $\sigma_{e x}^{V S I}$ or $\sigma_{e x}^{A F M}$ was unlikely due to dehydration of

403 ASSLs. After applying this constraint, the best fit to the XRR data for both methods (referred to

404 as "AFM/VSI roughness fit" and "AFM roughness fit" and shown as light and dark grey squares

405 in Figure 9B) based on the two remaining parameters (ASSL density and the roughness of the

406 inner interface) suggested that the density of the ASSL invariably increases with time, in contrast

407 with the conclusions reached from the analysis solely based on the $\chi^{2}$ minimization criterion.

408 However, the resulting density values exceeded those of pure amorphous silica $\left(\sim 20.6 \times 10^{-6} . \mathrm{A}^{-2}\right)$

409 and even those of unreacted labradorite $\left(23.5 \times 10^{-6} \cdot \mathrm{A}^{-2}\right)$. This likely unphysical result suggests

410 that the roughness values derived by both AFM and VSI overestimate the roughness reflected by

411 the XRR results. Consequently, we decided to rely on the well-documented " $\chi{ }^{2}$ fit" approach ${ }^{75}$,

412 which also enables direct comparison of our data with literature ${ }^{9,56}$. We note however that

413 surface roughness may artificially lower the layer apparent density and that further research

414 should be directed at better characterizing the in-situ evolution of surface roughness with

415 relevant experimental probes.

416 


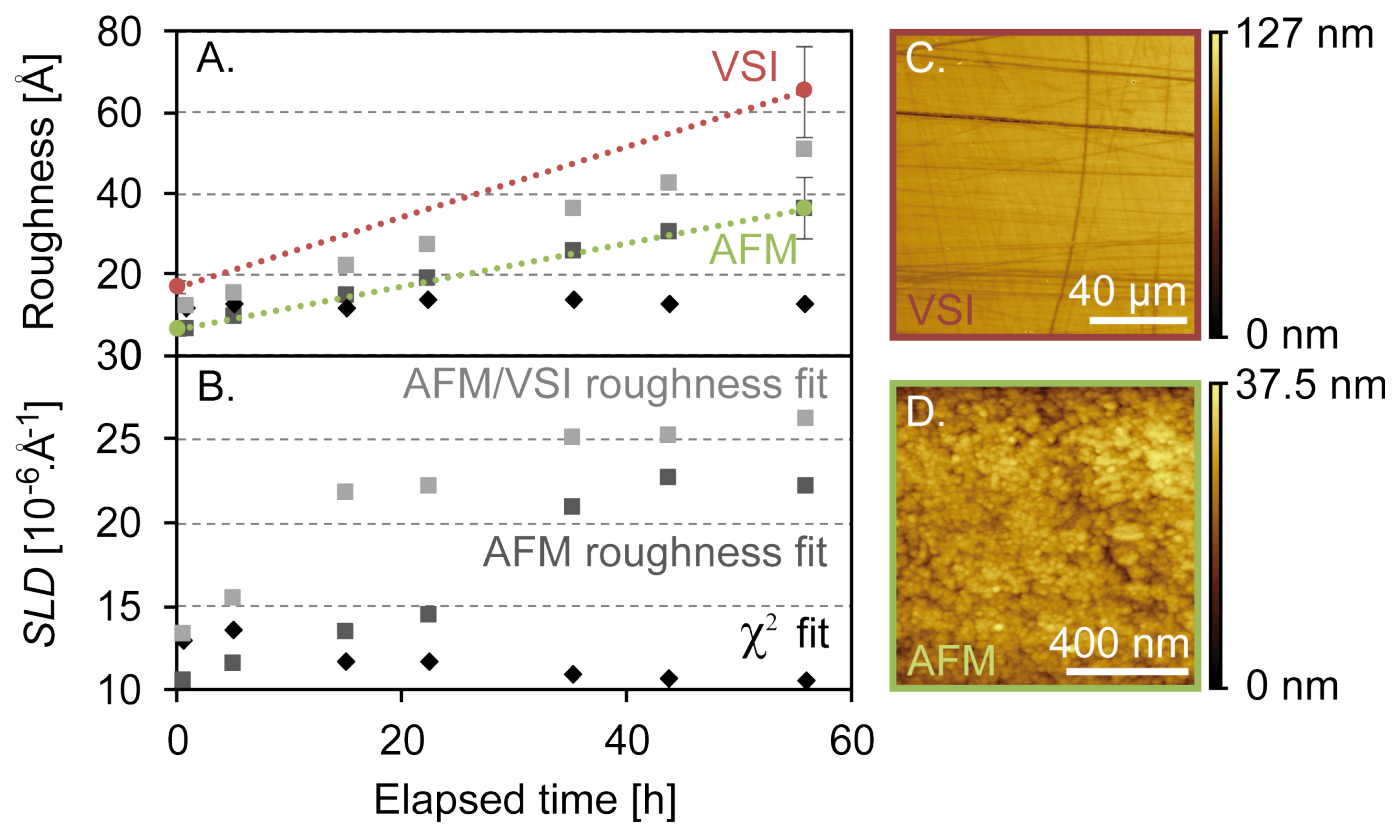

Elapsed time $[\mathrm{h}]$

418 Figure 9. Temporal evolution of roughness (A) and SLD (B) for experiment XRR6-3-80-0-001.

419 Black diamonds correspond to the best fits determined using the lowest $\chi^{2}$ value as the criterion

420 to assess the validity of the fit, grey squares correspond to best fits obtained using the lowest $\chi^{2}$

421 value after imposing at each temporal step the roughness at the outer interface based on

422 topography measurements. In that case, the roughness at the inner interface and the density of the

423 layer were the only adjustable parameters of the model (see text for details). For the "AFM

424 roughness fit" (dark grey squares), the evolution of the outer interface is assimilated to a linear

425 interpolation of AFM roughness measurements acquired before and after experiment. For the

426 "AFM/VSI roughness fit" (light grey squares), the evolution of the outer interface is associated

427 to the mean value between VSI and AFM measurements, their evolution being supposed linear

428 (see text). The sample roughness measured before and after experiment by VSI and AFM is

429 reported in red and green respectively in panel A. Typical fields of view are represented in 430 panels $\mathrm{C}$ and $\mathrm{D}$. 

XRR and VSI measurements

434 Traditionally, the mechanisms and rates of mineral dissolution have been indirectly 435 monitored through the evolution of fluid composition ${ }^{79,80}$. In these studies, the non436 stoichiometry of elemental release was used to indirectly probe the formation of ASSLs at the 437 fluid-mineral interface ${ }^{10,28,31}$. As mentioned in the introduction, this indirect approach suffers 438 from high uncertainties when it comes to determining the evolution of ASSL thickness and 439 density, particularly at low dissolution rates, principally due to the difficulty of accurately 440 determining the stoichiometry of the small elemental release and, also, of constraining the 441 evolving reacting surface area. Our results show that this challenge can be circumvented, to some 442 extent, by using a combination of XRR and VSI measurements to characterize the rate of ASSL 443 formation at the labradorite-water interface. We were able to detect the formation of ASSLs at 444 the surface of labradorite in all tested conditions, in agreement with previous results on a variety 445 of silicate minerals including feldspars ${ }^{20}$. We also probed independently the reactivity of the 446 outer fluid/layer interface and of the inner layer/mineral interface in-situ. This provided an 447 accurate picture of the temporal evolution of the fluid-mineral interface (Figure 7, Figure S3), 448 which enabled unravelling the reaction kinetics. Our results indicate a reaction order with respect 449 to hydrogen ion (corresponding to the power to which the activity of this ion is raised, see eq. 3 450 and Figure 8 ) of about 0.77 for the overall dissolution process of labradorite occurring at the 451 inner interface, which is slightly higher than values previously reported for this mineral452 typically 0.6 - but consistent with the expected range within the feldspar series, typically up to 4531.0 for bytownite ${ }^{80}$. Slight differences with previously published data are expected since the 
454 protocol used here investigates the reactivity of single cleavage planes, which is known to differ 455 from that of bulk mineral powders ${ }^{78}$.

456 Most of the mean density values of ASSLs estimated from XRR data fall between 1.29

457 g.cm ${ }^{-3}$ and 1.89 g.cm ${ }^{-3}$. These measured density values are consistent with the theoretical values

458 for a medium composed of spheres of pure amorphous silica organized within an aqueous

459 medium with either a "dense packing" (face-centered cubic) or a "minimal packing" (estimated

460 from 2D analysis, see "Reactivity and evolution of outer interface" section), corresponding to

461 water-silica mass ratios of 63:10 and 10:14, respectively. They may alternatively be associated

462 with a homogeneous product of hydrated silica. Analysis of samples "XRR3-2.5-80-0-001" and

463 “XRR4-2.5-80-0-010” yielded XRR density estimates exceeding the value reported for bulk

464 anhydrous $\mathrm{SiO}_{2}\left(2.2\right.$ g.cm ${ }^{-3}$, cf. Iler $\left.{ }^{81}\right)$. Such high values may arise from samples with curved 465 interfaces causing total reflection intensity to be detected at angles exceeding the actual critical 466 angle $^{9}$ and are therefore not further discussed. Overall, our results indicate that the ASSL is 467 either hydrated or accommodates significant porosity, which, together with the botryoidal texture 468 of the outer interface, is consistent with the hypothesis that ASSL formation involves significant 469 dissolution-reprecipitation ${ }^{20,59}$.

470 Our experiments show that the dissolution rate of the pristine mineral is impacted by the 471 saturation state of the solution with respect to amorphous silica (Figure 6). From a pure 472 thermodynamic standpoint, only the dissolution rate of the ASSL (and not labradorite) should be 473 impacted by the aqueous silica concentration, because the experiments were conducted at far474 from-equilibrium conditions with respect to labradorite. This result indicates that the intrinsic 475 dissolution rate of ASSL significantly modulates the reactivity of labradorite (see section 476 "Passivation by surface layers" below). 
The dissolution rate of the ASSL was not directly probed by our XRR measurements,

478 which only probed ASSL thickness. However, the need for frequent $z$-axis realignment 479 throughout the dissolution experiment to match perfect $\theta-2 \theta$ reflection conditions at the surface 480 of the sample provides additional evidence of the progressive retreat of the outer interface, which 481 was tracked more precisely by VSI on separate samples. Our VSI results indicate that the mean 482 ASSL dissolution rate ranged from $1.07 \times 10^{-7} \mathrm{~mol} \mathrm{~m}^{-2} \mathrm{~s}^{-1}$ at $\mathrm{pH}=1.5$ to $1.46 \times 10^{-9} \mathrm{~mol} \mathrm{~m}^{-2} \mathrm{~s}^{-1}$ 483 at $\mathrm{pH}=4$ at $80^{\circ} \mathrm{C}$ in silica-poor solutions. These values are in good agreement with the 484 dissolution rate of amorphous silica observed in other studies. For example, linear extrapolation 485 of our experimental $\log ($ rate $)=f(p H)$ model is consistent (within a factor of $0.5 \log$ unit) with the 486 results of Icenhower and Dove (2000)Icenhower and Dove ${ }^{82}$ for dilute solutions at $\mathrm{pH}=5.7$ at $48780^{\circ} \mathrm{C}$ and also (within the same $0.5 \log$ units factor) with estimates based on Rimstidt and Barnes 488 (2000)Rimstidt and Barnes ${ }^{83}$ at a pH comprised between 6.5 and 7.1 at $80^{\circ} \mathrm{C}$. In addition, our 489 dissolution rates are consistently 2 to 3 orders of magnitude greater than that of quartz ${ }^{84}$, as 490 expected for amorphous $\mathrm{SiO}_{2}$.

491 Finally, the observation of surface layer dissolution with a fluid at saturation with respect 492 to amorphous silica supports previous hypothesis suggesting either an enhanced solubility of the 493 ASSL formed on silicates such as wollastonite compared to pure amorphous silica, or that 494 ASSLs dissolve by a different mechanism than amorphous silica ${ }^{6}$. This result however is at odds 495 with observations conducted on ASSLs formed on diopside ${ }^{85}$, where the solubility of the ASSLs 496 was suggested to be close to that of $\alpha$-cristobalite.

497 In summary, our results suggest that ASSLs formed on labradorite have slightly higher 498 solubility than amorphous $\mathrm{SiO}_{2}$ but similar dissolution rates. Since the solubility of hydrated 499 amorphous silica would theoretically be decreased compared to pure amorphous silica according 
500 to ${ }^{81}$, we conclude that the presence in our system of a homogenous layer of hydrated amorphous 501 silica is unlikely. Instead, a layer composed of a rather dense packing of silica-rich spheres 502 surrounded by aqueous solution may form, which would be consistent with a mechanism 503 whereby a botryoidal texture propagates through the layer. Whether the packing, size, or 504 composition of the spheres changes through time still needs to be determined.

505 As shown in Figure 5, the dissolution rate of ASSL in an acidic solution is also pH506 dependent, meaning that hydrogen ions are involved, to some extent, in the dissolution reaction. 507 This feature is generally unexpected for pure amorphous silica ${ }^{82}$. This supports the hypothesis 508 that ASSLs formed on labradorite at $\mathrm{pH}>1.5$ may not consist of pure hydrated $\mathrm{SiO}_{2}{ }^{14}$. In 509 addition, when the fluid is saturated with respect to amorphous silica (aqueous silica 510 concentrations typically of $5.2 \times 10^{-3} \mathrm{M}$ ), the reaction order with respect to hydrogen ion is 511 reduced, showing a reduced impact of the layer on the dissolution rate at more acidic $\mathrm{pH}$ values

512 (Figure 8). This is consistent with the formation of different layer-forming phases depending on 513 the $\mathrm{pH}$ conditions, the passivating effect of which would be enhanced at conditions closer to 514 neutrality.

515 The estimate for the activation energy of labradorite dissolution in the present 516 experiments is $\sim 58 \mathrm{~kJ} \mathrm{~mol}^{-1}$, which is similar to those typically reported for labradorite, at $\sim 42 \mathrm{~kJ}$ $517 \mathrm{~mol}^{-180}$. Finally, no difference was detected between the layer growth rate recorded on (001) and 518 (010) faces (Figure 7A). Since no anisotropy of dissolution is expected from amorphous phases 519 such as those constituting the ASSL, we conclude that no compelling evidence of dissolution 520 anisotropy for labradorite could be evidenced here. 
Our approach, involving a continuously hydrated fluid-mineral interface, is not

524 completely analogous to environmental settings where minerals, glasses, and concrete materials

525 experience drying/wetting cycles. The effect of drying was therefore investigated at three $\mathrm{pH}$

526 conditions (experiments XRR9-1.5-80-SiO2-001, XRR11-2.5-80-SiO2-001, and XRR13-3-80-

$527 \mathrm{SiO} 2-001)$. As reported in Table S3, drying of ASSLs tends to decrease their apparent density,

528 while having no clear impact on their thickness or roughness. The porosity, defined as the

529 volume proportion of fluid or air in the ASSL, was estimated from SLD values measured in-situ

530 or after drying, respectively. The layer was considered to a first approximation as a porous

531 amorphous silica phase, as suggested by its reactivity (cf. previous section). This analysis

532 suggests a drop in the porosity during drying for the experiment conducted under acid conditions

$533(\mathrm{pH}=1.5)$ and an increase of the density at milder $\mathrm{pH}(\mathrm{pH}>1.5)$ (Table 1). Such behavior cannot

534 be explained by a prospective collapse or dilatation of the porous network during drying since no

535 significant evolution of the thickness of the ASSL could be observed. Alternatively, precipitation

536 of distinct phases from the poral solution, depending on its $\mathrm{pH}$, could explain either the sealing

537 of the porosity by growth and coalescence of the particles forming the layer at $\mathrm{pH}=1.5$ (which

538 can bear higher concentrations of dissolved species), while the precipitation of platelet-like

539 phases could open-up the porosity of layers formed at milder conditions, which are suspected to

540 exhibit higher Al-content ${ }^{14}$. This hypothesis is supported by the larger discrepancy existing

541 between the porosity measured in-situ and after drying for the experiment at $\mathrm{pH}=3(22.5 \%)$ than

542 at $\mathrm{pH}=2.5(10.5 \%)$. The preliminary results obtained with our approach open interesting avenues

543 for the investigation of dry/wet cycles on ASSL textural properties that still need to be explored 544 in depth. 


\begin{tabular}{ccccc}
\hline Measurement & \multicolumn{2}{c}{ In-situ } & \multicolumn{2}{c}{ dried } \\
\hline Experiment & SLD Layer & Porosity & SLD Layer & Porosity \\
& {$\left[10^{-6} \cdot A^{-2}\right]$} & \%Water $($ Vol. $)$ & {$\left[10^{-6} \cdot A^{-2}\right]$} & \%Air (Vol.) \\
\hline XRR9-1.5-80-SiO2-001 & 14.7 & 43 & 14.0 & 25 \\
XRR11-2.5-80-SiO2-001 & 15.5 & 34 & 10.3 & 45 \\
XRR13-3-80-SiO2-001 & 13.2 & 60 & 3.4 & 82 \\
\hline
\end{tabular}

547 Table 1: Scattering length densities (SLD) and associated estimate of layer's porosity measured 548 in-situ or after drying.

\section{Passivation by surface layers}

The passivating effect of ASSLs, which results in the reduction of the dissolution rate of 552 primary silicates, has been evidenced in a variety of geological or geochemical contexts ${ }^{2,9,14,21,61}$.

553 In the present study, lower dissolution rates were observed on a reference silicate material 554 (labradorite feldspar) during experiments conducted with silica-rich solutions compared to those 555 that used silica-poor solutions at equivalent $\mathrm{pH}$ values. Such contrasting behavior cannot be 556 explained using current analysis approaches, which consist of relating physico-chemical

557 properties of the bulk fluid (e.g. $T, \mathrm{pH}$, and other ion activities) to the overall dissolution rate of 558 the silicate materials $\left(R_{\min }\right)$, following:

$$
R_{\min }=\left[\sum_{i} A_{i, \min } \cdot \exp \left(\frac{-E_{a, \min }^{i}}{R T}\right) \cdot a_{i}^{n_{i, \min }}\right]\left(1-\exp \left(\frac{S * \Delta G r}{R T}\right)\right)
$$

559 where $A_{i, \min }$ is an Arrhenius pre-exponential factor; $E_{a, \min }^{i}, a_{i}$, and $n_{i, \min }$ are the activation

560 energy, activity, and reaction order with respect to reactive species $i ; R$ is the ideal gas constant;

$561 T$ is absolute temperature; and $\Delta G r$ and $S$ are the Gibbs free energy of the dissolution reaction 562 and a dimensionless empirical factor. According to the classical theoretical framework of

563 mineral dissolution kinetics, the affinity term $\left(1-\exp \left(\frac{s * \Delta G r}{R T}\right)\right)$ equals $\sim 1$ in our experiments 
564 since the aqueous solutions were at far-from-equilibrium conditions with respect to the 565 dissolution of the primary phase $\left(\Delta G_{r}<-41.8 \mathrm{~kJ} \mathrm{~mol}^{-1}\right.$, Table S1). Note that this statement holds

566 true even if more sophisticated empirical functions are used, such as the one determined by 567 Taylor, et al. ${ }^{46}$ for labradorite. Moreover, in acidic conditions $(\mathrm{pH} \leq 4)$, the only reactive species 568 to be considered is $\mathrm{H}^{+}$. In short, no effect of the activity of dissolved $\mathrm{SiO}_{2}$ is anticipated for our 569 system, which is at odds with labradorite dissolution rate in silica-rich solutions being 5 to 50 570 times lower compared with silica-poor solutions as described above. Therefore, we conclude that 571 the composition of the solution at the inner (labradorite/ASSL) interface must be different from 572 that of the bulk solution, consistent with other recent studies 86 . In particular, since temperature 573 was maintained constant, we conclude that the two remaining parameters able to influence the 574 kinetic dissolution rate (namely $\mathrm{pH}$ and/or ion concentration) might be significantly higher at the 575 inner interface than in the fluid at least for the silica-rich experiments, and that this discrepancy 576 is higher for experiments conducted in silica-rich fluid than for silica-poor experiments. This 577 hypothesis is supported by the fact that the rate drop observed when saturating the fluid with 578 respect to amorphous silica is more marked for experiments conducted at higher $\mathrm{pH}$, where fluid 579 composition is more sensitive to proton consumption and cation release by the dissolution 580 process. Of note, at $\mathrm{pH}=4$ with high background concentrations of dissolved silica, pore fluid 581 can only accommodate about $30 \mathrm{ppb}$ of $\mathrm{Al}^{3+}$ and $\mathrm{Ca}^{2+}$ before reaching the close-to-equilibrium 582 regime domain with respect to labradorite dissolution defined by Taylor, et al. ${ }^{46}$. These 583 conclusions may be related to the overall increase of density observed for most experiments 584 conducted in silica-rich solutions, which may indicate a decrease in the ASSL's porosity and, 585 possibly, transport properties as previously reported for the dissolution of wollastonite ${ }^{9}$. 586 Decreasing density observed for XRR9 and XRR11 experiments suggests however that density 
may not fully explain transport properties inside ASSLs and that other parameters controlling the

588 spatial organization of the porous network (e.g. tortuosity) may need to be investigated in future

589 using microscopy and surface-sensitive scattering techniques coupled with numerical modeling.

590 In summary, we hypothesize that the decrease of the dissolution rate of labradorite

591 minerals in silica-rich fluids was due to the passivation by ASSLs formed under these conditions,

592 which decreased the transport properties of reactive species and reaction products through the

593 layer, ultimately leading to higher local $\mathrm{pH}$ and/or ion concentration at the inner layer/mineral

594 interface.

595 On the contrary, for experiments conducted in silica-poor fluids, no clear evidence of 596 passivation and ASSL densification was noted. Two possible explanations can be put forward to 597 explain this observation, in contrast with previous data where passivation could be directly 598 observed ${ }^{14,21}$. First, it is likely that the emergence of passivating properties requires a certain 599 minimal duration for the layer to densify, also called "maturing time" 87 . Analogous time600 dependent processes have been previously observed for amorphous phases such as pregibbsite 601 gels ${ }^{88}$. Of note, no clear temporal decrease of the dissolution rate was seen on the timescale of 602 our experiments. Secondly, it is possible that elemental release from accessory phases included 603 in a given primary mineral or assemblage, and especially iron-containing minerals, plays an 604 important role in the buildup of passivating layers. Indeed, formation of a hematite-amorphous 605 silica assemblage, exhibiting passivating properties due to strong Fe(III)-Si chemical interactions $606 \quad 62,89$ is one of the few clearly identified mechanism of silicate passivation to date. Contrary to the 607 present study, both in Wild, et al. ${ }^{14}$ and Daval, et al. ${ }^{21}$ where passivation effect could be 608 observed, the labradorite used contained Fe-bearing mineral inclusions. Such hypothesis, 
609 however, would still need to be demonstrated, especially regarding transport of iron from

610 accessory phases to the iron-free silicate surface.

611 Existing dissolution rate laws are based almost exclusively on laboratory experiments

612 consisting in immersing mineral grains in reactive fluids at high temperature and low $\mathrm{pH}$

613 conditions and recording dissolution through elemental release into solution. The methodology

614 developed here provides complementary data that can help shed light on silicate dissolution in

615 natural settings. In particular, we were able to precisely quantify two properties critical to

616 extrapolating laboratory results to natural settings and larger time and spatial scales: the rates of

617 dissolution of the pristine mineral and of the ASSL and their associated activation energies. In

618 addition, we provided indirect evidence for changes in the pore fluid chemistry of the ASSL,

619 possibly related to the apparent transport properties of this phase. With regards to implications

620 for silicate weathering in field conditions, our results suggest that circum-neutral $\mathrm{pH}$ values,

621 silica-rich fluids, the presence of complex mineralogical assemblages including Fe-rich phases,

622 long time scales, and drying-wetting cycles all tend to favor the formation of ASSLs with

623 reduced porosity and transport properties. The methodology developed here should therefore

624 enable to better characterize the physicochemical evolution of the silica-rich surface layers on a

625 wide range of silicate materials, enabling to relate the dissolution rates of silicate materials

626 observed at the macroscale to the transport properties of nanoporous silica-rich layers, which

627 have been extensively studied both from theoretical and experimental perspectives ${ }^{57,67-71 .}$

\section{CONCLUSIONS}

630 The present study tested a novel methodology to probe in-situ the formation and 631 properties of amorphous silica-rich surface layers (ASSLs) developed at a fluid-silicate interface. 
632 Our approach enabled precise quantification of the formation of ASSLs on labradorite feldspar, a

633 silicate mineral representative of the continental crust. We quantified ASSL density, thickness,

634 and roughness by X-ray reflectivity while independently probing ASSL reactivity by vertical

635 scanning interferometry. Our results suggest that the ASSLs have a significant effect on the

636 dissolution rate of the primary mineral: our experiments revealed a drop in the dissolution rate of

637 labradorite in silica-rich solutions compared to silica-poor solutions, where both conditions were

638 far-from equilibrium with respect to the dissolution of this primary phase in the bulk fluid. Our

639 results suggest that ASSLs formed in silica-rich fluids have distinct transport properties resulting

640 in either higher ion activities, higher $\mathrm{pH}$, or both in the pore solution controlling the dissolution

641 of the primary phase.

642 Overall, our findings underline the need for an improved understanding of the processes

643 controlling local physico-chemical parameters at the interface with the dissolving silicate, which

644 may differ from those recorded in bulk fluid. The methodology developed here is a valuable tool

645 for investigating silicate dissolution. In addition to complementary from bulk fluid analysis, it

646 has the potential to enable the determination of the relevant parameters (e.g. local fluid $\mathrm{pH}$ and

647 saturation conditions actually driving the dissolution process at the inner layer-silicate interface)

648 for onsite applications and important industrial processes.

650 AUTHOR INFORMATION

651 Corresponding Author

$652 *$ Andlinger Center for Energy and the Environment, Princeton University, Princeton, NJ 08544, 653 USA; e-mail: bwild@princeton.edu

\section{Author Contributions}


655 The manuscript was written through contributions of all authors. All authors have given approval 656 to the final version of the manuscript.

\section{ACKNOWLEDGMENT}

658 A. Aubert and V. Magnin are acknowledged for their technical support during synchrotron 659 measurement campaigns. A. Putnis, J. Hövelmann, K. Czaja and the Mineralogical \& Geological

660 Museum of Harvard University are warmly acknowledged for providing labradorite samples 661 (Ref. MGMH\#135998). This project was funded by the VALVE project (EC2CO-BIOHEFECT

662 program coordinated by the CNRS-INSU) attributed to D. Daval. B. Wild was supported by 663 Princeton University's Andlinger Center for Energy and Environment through its Distinguished 664 Postdoctoral Fellows program. The relevance of this study and the quality of the manuscript was 665 significantly improved by insightful comments from Thorsten Geisler-Wierwille, Moritz 666 Fritzsche and two anonymous reviewers.

\section{ABBREVIATIONS}

669 ASSLs, amorphous silica-rich surface layers; VSI, vertical scanning interferometry; XRR, X-ray 670 reflectivity;

671 TST, transition state theory; BET, Brunauer-Emmett-Teller; AFM, atomic force microscopy; 672 EBSD, electron backscatter diffraction; SEM, scanning electron microscope; PTFE,

673 polytetrafluoroethylene; RTV, room-temperature-vulcanizing; ESRF, European synchrotron

674 radiation facility; SLD, scattering length density; $\mathrm{Ab}$, Albite $\left(\mathrm{NaAlSi}_{3} \mathrm{O}_{8}\right)$; $\mathrm{An}$, Anorthite $\left(\mathrm{CaAl}_{2}\right.$

$\left.675 \mathrm{Si}_{2} \mathrm{O}_{8}\right)$; Or, Orthoclase $\left(\mathrm{KAlSi}_{3} \mathrm{O}_{8}\right)$. 
678 Summary of experiments conducted in this study, tables of best fit parameters associated to

679 reflectivity data, Table of surface retreat measured by VSI, example of treatment of reflectivity

680 data, AFM topography of a reacted portion of labradorite.

681

\section{REFERENCES}

6831 Bearat, H., McKelvy, M. J., Chizmeshya, A. V. G., Gormley, D., Nunez, R., Carpenter,

684 R. W., Squires, K. \& Wolf, G. H. Carbon sequestration via aqueous olivine mineral carbonation:

685 Role of passivating layer formation. Environ. Sci. Technol. 40, 4802-4808 (2006).

6862 Daval, D., Sissmann, O., Menguy, N., Saldi, G. D., Guyot, F., Martinez, I., Corvisier, J., 687 Garcia, B., Machouk, I., Knauss, K. G. et al. Influence of amorphous silica layer formation on 688 the dissolution rate of olivine at $90^{\circ} \mathrm{C}$ and elevated pCO(2). Chem. Geol. 284, 193-209 (2011).

6893 Johnson, N. C., Thomas, B., Maher, K., Rosenbauer, R. J., Bird, D. \& Brown Jr, G. E.

690 Olivine dissolution and carbonation under conditions relevant for in situ carbon storage. Chem.

691 Geol. 373, 93-105 (2014).

6924 Maher, K., Johnson, N. C., Jackson, A., Lammers, L. N., Torchinsky, A. B., Weaver, K.

693 L., Bird, D. K. \& Brown Jr, G. E. A spatially resolved surface kinetic model for forsterite

694 dissolution. Geochim. Cosmochim. Acta 174, 313-334 (2016).

6955 Daval, D., Martinez, I., Corvisier, J., Findling, N., Goffe, B. \& Guyot, F. Carbonation of 696 Ca-bearing silicates, the case of wollastonite: Experimental investigations and kinetic modeling.

697 Chem. Geol. 265, 63-78 (2009).

6986 Weissbart, E. J. \& Rimstidt, D. J. Wollastonite: Incongruent dissolution and leached layer

699 formation. Geochim. Cosmochim. Acta 64, 4007-4016 (2000). 
7007 Ruiz-Agudo, E., Putnis, C. V., Rodriguez-Navarro, C. \& Putnis, A. Mechanism of

701 leached layer formation during chemical weathering of silicate minerals. Geology 40, 947-950

702 (2012).

7038 Schott, J., Pokrovsky, O. S., Spalla, O., Devreux, F., Gloter, A. \& Mielczarski, J. A.

704 Formation, growth and transformation of leached layers during silicate minerals dissolution: The

705 example of wollastonite. Geochim. Cosmochim. Acta 98, 259-281 (2012).

7069 Daval, D., Bernard, S., Rémusat, L., Wild, B., Guyot, F., Micha, J. S., Rieutord, F.,

707 Magnin, V. \& Fernandez-Martinez, A. Dynamics of altered surface layer formation on dissolving

708 silicates. Geochim. Cosmochim. Acta 209, 51-69 (2017).

70910 Lagache, M. New data on the kinetics of the dissolution of alkali feldspars at $200^{\circ} \mathrm{C}$ in

710 CO2 charged water. Geochim. Cosmochim. Acta 40, 157-161 (1976).

71111 Casey, W. H., Westrich, H. R., Massis, T., Banfield, J. F. \& Arnold, G. W. The surface of

712 labradorite feldspar after acid hydrolysis. Chem. Geol. 78, 205-218 (1989).

71312 Casey, W. H., Westrich, H. R., Banfield, J. F., Ferruzzi, G. \& Arnold, G. W. Leaching

714 and reconstruction at the surface of dissolving chain-silicate minerals. Nature 366, 253-256

715 (1993).

71613 Hellmann, R., Penisson, J.-M., Hervig, R. L., Thomassin, J.-H. \& Abrioux, M.-F. An

717 EFTEM/HRTEM high-resolution study of the near surface of labradorite feldspar altered at acid

$718 \mathrm{pH}$ : evidence for interfacial dissolution-reprecipitation. Physics and Chemistry of Minerals 30,

719 192-197(2003).

72014 Wild, B., Daval, D., Guyot, F., Knauss, K. G., Pollet-Villard, M. \& Imfeld, G. pH-

721 dependent control of feldspar dissolution rate by altered surface layers. Chem. Geol. 442, 148-

722159 (2016). 
72315 Cailleteau, C., Angeli, F., Devreux, F., Gin, S., Jestin, J., Jollivet, P. \& Spalla, O. Insight

724 into silicate-glass corrosion mechanisms. Nature Materials 7, 978-983 (2008).

72516 Verney-Carron, A., Gin, S., Frugier, P. \& Libourel, G. Long-term modeling of alteration-

726 transport coupling: Application to a fractured Roman glass. Geochim. Cosmochim. Acta 74,

$727 \quad 2291-2315(2010)$.

72817 Geisler, T., Nagel, T., Kilburn, M. R., Janssen, A., Icenhower, J. P., Fonseca, R. O. C.,

729 Grange, M. \& Nemchin, A. A. The mechanism of borosilicate glass corrosion revisited.

730 Geochim. Cosmochim. Acta 158, 112-129 (2015).

73118 Gin, S., Jollivet, P., Fournier, M., Angeli, F., Frugier, P. \& Charpentier, T. Origin and

732 consequences of silicate glass passivation by surface layers. Nat. Commun. 6, 6360 (2015).

73319 Nugent, M. A., Brantley, S. L., Pantano, C. G. \& Maurice, P. A. The influence of natural

734 mineral coatings on feldspar weathering. Nature 395, 588-591 (1998).

73520 Hellmann, R., Wirth, R., Daval, D., Barnes, J.-P., Penisson, J.-M., Tisserand, D., Epicier,

736 T., Florin, B. \& Hervig, R. L. Unifying natural and laboratory chemical weathering with

737 interfacial dissolution-reprecipitation: A study based on the nanometer-scale chemistry of fluid-

738 silicate interfaces. Chem. Geol. 294-295, 203-216 (2012).

73921 Daval, D., Calvaruso, C., Guyot, F. \& Turpault, M.-P. Time-dependent feldspar

740 dissolution rates resulting from surface passivation: Experimental evidence and geochemical

741 implications. Earth and Planetary Science Letters 498, 226-236 (2018).

74222 Monteiro, P. J. M., Miller, S. A. \& Horvath, A. Towards sustainable concrete. Nature

743 Materials 16, 698 (2017). 
74423 Gin, S., Collin, M., Jollivet, P., Fournier, M., Minet, Y., Dupuy, L., Mahadevan, T.,

745 Kerisit, S. \& Du, J. Dynamics of self-reorganization explains passivation of silicate glasses. Nat.

746 Commun. 9, 2169 (2018).

74724 Park, A.-H. A. \& Fan, L.-S. CO2 mineral sequestration: physically activated dissolution 748 of serpentine and pH swing process. Chemical Engineering Science 59, 5241-5247 (2004).

74925 Noiriel, C. \& Daval, D. Pore-scale geochemical reactivity associated with CO2 storage:

750 new frontiers at the fluid-solid interface. Accounts of Chemical Research 50, 759-768 (2017).

75126 Correns, C. W. \& von Engelhardt, W. Neue Untersuchungen über die Verwitterung des

752 Kalifeldspates. Naturwissenschaften 26, 137-138 (1938).

75327 Luce, R. W., Bartlett, R. W. \& Parks, G. A. Dissolution kinetics of magnesium silicates.

754 Geochim. Cosmochim. Acta 36, 33-50 (1972).

75528 Paces, T. Chemical characteristics and equilibration in natural water-felsic rock-CO2

756 system. Geochim. Cosmochim. Acta 36, 217-240 (1972).

75729 Muir, I. J., Michael Bancroft, G. \& Wayne Nesbitt, H. Characteristics of altered

758 labradorite surfaces by SIMS and XPS. Geochim. Cosmochim. Acta 53, 1235-1241 (1989).

75930 Petit, J.-C., Dran, J.-C., Schott, J. \& Mea, G. D. New evidence on the dissolution

760 mechanism of crystalline silicates by MeV ion beam techniques. Chem. Geol. 76, 365-369

761 (1989).

76231 Hellmann, R., Eggleston, C. M., Hochella, M. F. J. \& Crerar, D. A. The formation of

763 leached layers on albite surfaces during dissolution under hydrothermal conditions. Geochim.

764 Cosmochim. Acta 54, 1267-1281 (1990).

76532 Inskeep, W. P., Nater, E. A., Bloom, P. R., Vandervoort, D. S. \& Erich, M. S.

766 Characterization of laboratory weathered labradorite surfaces using X-ray photoelectron 
767 spectroscopy and transmission electron microscopy. Geochim. Cosmochim. Acta 55, 787-800

768 (1991).

76933 Muir, I. J. \& Nesbitt, H. W. Effects of aqueous cations on the dissolution of labradorite

770 feldspar. Geochim. Cosmochim. Acta 55, 3181-3189 (1991).

77134 Shotyk, W. \& Nesbitt, H. W. Incongruent and congruent dissolution of plagioclase

772 feldspar - effect of feldspar compositionand ligand complexation. Geoderma 55, 55-78 (1992).

77335 Shotyk, W. \& Metson, J. B. Secondary ion mass spectrometry (SIMS) and its application

774 to chemical weathering. Reviews of Geophysics 32, 197-220 (1994).

77536 Schweda, P., Sjoberg, L. \& Sodervall, U. Near-surface composition of acid-leached

776 labradorite investigated by SIMS. Geochim. Cosmochim. Acta 61, 1985-1994 (1997).

77737 Chen, Y. \& Brantley, S. L. Dissolution of forsteritic olivine at $65^{\circ} \mathrm{C}$ and $2<\mathrm{pH}<5$. Chem.

778 Geol. 165, 267-281 (2000).

77938 Nesbitt, H. W. \& Skinner, W. M. Early development of Al, Ca, and Na compositional 780 gradients in labradorite leached in $\mathrm{pH} 2 \mathrm{HCl}$ solutions. Geochim. Cosmochim. Acta 65, 715-727

781 (2001).

78239 Putnis, C. V., Tsukamoto, K. \& Nishimura, Y. Direct observations of pseudomorphism:

783 compositional and textural evolution at a fluid-solid interface. Am. Miner. 90, 1909-1912 (2005).

78440 Jordan, G., Higgins, S. R., Eggleston, C. M., Swapp, S. M., Janney, D. E. \& Knauss, K.

785 G. Acidic dissolution of plagioclase: in-situ observations by hydrothermal atomic force

786 microscopy. Geochim. Cosmochim. Acta 63, 3183-3191 (1999).

78741 Aagaard, P. \& Helgeson, H. C. Thermodynamic and kinetic constraints on reaction-rates

788 among minerals and aqueous solutions. 1. Theoretical considerations. American Journal of

789 Science 282, 237-285 (1982). 
$79042 \quad$ Berner, R. A. \& Holdren, G. R. Mechanism of feldspar weathering - some observational 791 evidence. Geology 5, 369-372 (1977).

79243 Berner, R. A. \& Holdren, G. R. Mechanism of feldspar weathering .2. Observations of

793 feldspars from soils. Geochim. Cosmochim. Acta 43, 1173-1186 (1979).

79444 Holdren, G. R. \& Berner, R. A. Merchanism of feldspar weathering. 1. Experimental 795 studies. Geochim. Cosmochim. Acta 43, 1161-1171 (1979).

79645 Oelkers, E. H., Schott, J. \& Devidal, J.-L. The effect of aluminum, pH, and chemical 797 affinity on the rates of aluminosilicate dissolution reactions. Geochim. Cosmochim. Acta 58, 798 2011-2024 (1994).

79946 Taylor, A. S., Blum, J. D. \& Lasaga, A. C. The dependence of labradorite dissolution and 800 Sr isotope release rates on solution saturation state. Geochim. Cosmochim. Acta 64, 2389-2400 801 (2000).

80247 Nagy, K. L., Blum, A. E. \& Lasaga, A. C. Dissolution and precipitation kinetics of 803 kaolinite at 80 degrees $\mathrm{C}$ and $\mathrm{pH} 3$; the dependence on solution saturation state. American 804 Journal of Science 291, 649-686 (1991).

80548 Lasaga, A. C. in Chemical weathering rates of silicate minerals Vol. 31 (eds Art F. 806 White \& Susan L. Brantley) 23-86 (1995).

80749 Grambow, B. \& Muller, R. First-order dissolution rate law and the role of surface layers 808 in glass performance assessment. J. Nucl. Mater. 298, 112-124 (2001).

$80950 \quad$ Bourcier, W. L., Peiffer, D. W., Knauss, K. G., McKeegan, K. D. \& Smith, D. K. A

810 Kinetic model for $\mathrm{B} \backslash$ borosilicate glass dissolution based on the dissolution affinity of a surface 811 alteration layer. MRS Online Proceedings Library Archive 176, 1-10 (1989). 
81251 Oelkers, E. H. \& Schott, J. Experimental study of anorthite dissolution and the relative

813 mechanism of feldspar hydrolysis. Geochim. Cosmochim. Acta 59, 5039-5053 (1995).

81452 Daux, V., Guy, C., Advocat, T., Crovisier, J. L. \& Stille, P. Kinetic aspects of basaltic

815 glass dissolution at $90^{\circ} \mathrm{C}$ : role of aqueous silicon and aluminium. Chem. Geol. 142, 109-126

816 (1997).

81753 Oelkers, E. H. General kinetic description of multioxide silicate mineral and glass

818 dissolution. Geochim. Cosmochim. Acta 65, 3703-3719 (2001).

81954 Lüttge, A. Crystal dissolution kinetics and Gibbs free energy. Journal of Electron

820 Spectroscopy and Related Phenomena 150, 248-259 (2006).

82155 Devreux, F., Ledieu, A., Barboux, P. \& Minet, Y. Leaching of borosilicate glasses. II.

822 Model and Monte-Carlo simulations. J. Non-Cryst. Solids 343, 13-25 (2004).

82356 Rebiscoul, D., Van der Lee, A., Rieutord, F., Ne, F., Spalla, O., El-Mansouri, A., Frugier,

824 P., Ayral, A. \& Gin, S. Morphological evolution of alteration layers formed during nuclear glass

825 alteration: new evidence of a gel as a diffusive barrier. J. Nucl. Mater. 326, 9-18 (2004).

82657 Gin, S. p., Guittonneau, C., Godon, N., Neff, D., Rebiscoul, D., Cabié, M. \& Mostefaoui,

827 S. Nuclear glass durability: new insight into alteration layer properties. The Journal of Physical

828 Chemistry C 115, 18696-18706 (2011).

82958 Gin, S., Neill, L., Fournier, M., Frugier, P., Ducasse, T., Tribet, M., Abdelouas, A.,

830 Parruzot, B., Neeway, J. \& Wall, N. The controversial role of inter-diffusion in glass alteration.

831 Chem. Geol. 440, 115-123 (2016).

83259 Ruiz-Agudo, E., King, H. E., Patiño-López, L. D., Putnis, C. V., Geisler, T., Rodriguez-

833 Navarro, C. \& Putnis, A. Control of silicate weathering by interface-coupled dissolution-

834 precipitation processes at the mineral-solution interface. Geology 44, 567-570 (2016). 
83560 Sissmann, O., Daval, D., Brunet, F., Guyot, F., Verlaguet, A., Pinquier, Y., Findling, N.

$836 \&$ Martinez, I. The deleterious effect of secondary phases on olivine carbonation yield: Insight

837 from time-resolved aqueous-fluid sampling and FIB-TEM characterization. Chem. Geol. 357,

$838 \quad 186-202(2013)$.

83961 Saldi, G. D., Daval, D., Morvan, G. \& Knauss, K. G. The role of Fe and redox conditions

840 in olivine carbonation rates: an experimental study of the rate limiting reactions at 90 and $150{ }^{\circ} \mathrm{C}$

841 in open and closed systems. Geochim. Cosmochim. Acta 118, 157-183 (2013).

84262 Saldi, G. D., Daval, D., Guo, H., Guyot, F., Bernard, S., Le Guillou, C., Davis, J. A. \&

843 Knauss, K. G. Mineralogical evolution of Fe-Si-rich layers at the olivine-water interface during

844 carbonation reactions. Am. Miner. 100, 2655-2669 (2015).

84563 Hellmann, R., Cotte, S., Cadel, E., Malladi, S., Karlsson, L. S., Lozano-Perez, S., Cabié,

846 M. \& Seyeux, A. Nanometre-scale evidence for interfacial dissolution-reprecipitation control of

847 silicate glass corrosion. Nat Mater 14, 307-311 (2015).

84864 Casey, W. H. Glass and mineral corrosion dynamics and durability. Nature Materials 7,

849 930-932(2008).

85065 White, A. F. \& Brantley, S. L. The effect of time on the weathering of silicate minerals:

851 why do weathering rates differ in the laboratory and field? Chem. Geol. 202, 479-506 (2003).

85266 Fischer, C., Arvidson, R. S. \& Lüttge, A. How predictable are dissolution rates of

853 crystalline material? Geochim. Cosmochim. Acta 98, 177-185 (2012).

85467 Cailleteau, C., Devreux, F., Spalla, O., Angeli, F. \& Gin, S. Why do certain glasses with 855 a high dissolution rate undergo a low degree of corrosion? The Journal of Physical Chemistry C $856115,5846-5855(2011)$. 
85768 Bourg, I. C. \& Steefel, C. I. Molecular dynamics simulations of water structure and 858 diffusion in silica nanopores. The Journal of Physical Chemistry C 116, 11556-11564 (2012).

85969 Rébiscoul, D., Cambedouzou, J., Matar Briman, I., Cabié, M., Brau, H. P. \& Diat, O.

860 Water dynamics in nanoporous alteration layer coming from glass alteration: an experimental 861 approach. The Journal of Physical Chemistry C 119, 15982-15993 (2015).

86270 Neeway, J. J., Kerisit, S. N., Liu, J., Zhang, J., Zhu, Z., Riley, B. J. \& Ryan, J. V. Ion863 exchange interdiffusion model with potential application to long-term nuclear waste glass

864 performance. The Journal of Physical Chemistry C 120, 9374-9384 (2016).

86571 Collin, M., Gin, S., Dazas, B., Mahadevan, T., Du, J. \& Bourg, I. C. Molecular dynamics 866 simulations of water structure and diffusion in a $1 \mathrm{~nm}$ diameter silica nanopore as a function of 867 surface charge and alkali metal counterion identity. The Journal of Physical Chemistry C 122, $868 \quad 17764-17776(2018)$.

86972 Hövelmann, J., Austrheim, H. \& Putnis, A. Cordierite formation during the experimental 870 reaction of plagioclase with Mg-rich aqueous solutions. Contributions to Mineralogy and

871 Petrology 168, 1063 (2014).

87273 Arvidson, R. S., Beig, M. S. \& Lüttge, A. Single-crystal plagioclase feldspar dissolution 873 rates measured by vertical scanning interferometry. Am. Miner. 89, 51-56 (2004).

87474 Nečas, D. \& Klapetek, P. Gwyddion: an open-source software for SPM data analysis. 875 Central European Journal of Physics 10, 181-188 (2012).

87675 Nelson, A. Co-refinement of multiple-contrast neutron/X-ray reflectivity data using

877 MOTOFIT. Journal of Applied Crystallography 39, 273-276 (2006).

87876 Bowen, D. K., Tanner, B. K., Wormington, M., Panaccione, C., Matney Kevin, M. \& 879 Bowen, D. K. Characterization of structures from X-ray scattering data using genetic algorithms. 
880 Philosophical Transactions of the Royal Society of London. Series A: Mathematical, Physical 881 and Engineering Sciences 357, 2827-2848 (1999).

88277 Marquardt, D. An Algorithm for least-squares estimation of nonlinear parameters.

883 Journal of the Society for Industrial and Applied Mathematics 11, 431-441 (1963).

88478 Pollet-Villard, M., Daval, D., Ackerer, P., Saldi, G. D., Wild, B., Knauss, K. G. \& Fritz,

885 B. Does crystallographic anisotropy prevent the conventional treatment of aqueous mineral 886 reactivity? A case study based on K-feldspar dissolution kinetics. Geochim. Cosmochim. Acta 887 190, 294-308 (2016).

88879 Schott, J., Pokrovsky, O. S. \& Oelkers, E. H. The link between mineral 889 dissolution/precipitation kinetics and solution chemistry. Thermodynamics and Kinetics of 890 Water-Rock Interaction 70, 207-258 (2009).

$89180 \quad$ Palandri, J. L. \& Kharaka, Y. K. A compilation of rate parameters of water-mineral 892 interaction kinetics for application to geochemical modeling. 70 (U.S. Geological Survey, Open 893 File Report, 2004).

$89481 \quad$ Iler, R. K. The chemistry of silica : solubility, polymerization, colloid and surface 895 properties, and biochemistry / Ralph K. Iler. (Wiley, 1979).

89682 Icenhower, J. P. \& Dove, P. M. The dissolution kinetics of amorphous silica into sodium 897 chloride solutions: effects of temperature and ionic strength. Geochim. Cosmochim. Acta 64, 898 4193-4203 (2000).

89983 Rimstidt, J. D. \& Barnes, H. L. The kinetics of silica-water reactions. Geochim.

900 Cosmochim. Acta 44, 1683-1699 (1980). 
90184 Tester, J. W., Worley, W. G., Robinson, B. A., Grigsby, C. O. \& Feerer, J. L. Correlating 902 quartz dissolution kinetics in pure water from 25 to $625^{\circ} \mathrm{C}$. Geochim. Cosmochim. Acta 58, $903 \quad 2407-2420$ (1994).

90485 Daval, D., Hellmann, R., Saldi, G. D., Wirth, R. \& Knauss, K. G. Linking nm-scale 905 measurements of the anisotropy of silicate surface reactivity to macroscopic dissolution rate

906 laws: New insights based on diopside. Geochim. Cosmochim. Acta 107, 121-134, (2013).

90786 Geisler, T., Dohmen, L., Lenting, C. \& Fritzsche, M. B. K. Real-time in situ observations 908 of reaction and transport phenomena during silicate glass corrosion by fluid-cell Raman 909 spectroscopy. Nature Materials (2019).

$91087 \quad$ Bottero, J. Y., Cases, J. M., Fiessinger, F. \& Poirier, J. E. Studies of hydrolyzed

911 aluminium-chloride solutions. 1.Nature of aluminium species and composition of aqueous

912 solutions. J. Phys. Chem. 84, 2933-2939 (1980).

$91388 \quad$ McHardy, W. J. \& Thomson, A. P. Conditions for the formation of bayerite and gibbsite.

914 Mineralogical magazine 38, 358-368 (1971).

91589 Schott, J. \& Berner, R. A. X-Ray Photoelectron studies of the mechanism of iron silicate 916 dissolution during weathering. Geochim. Cosmochim. Acta 47, 2233-2240 (1983).

917 